\title{
essais en centrifugeuse et technique de la modélisation
}

\author{
centrifuge and modeling technology: a survey
}

\author{
R.F. SCOTT \\ California Institute of Technology *
}

Rev. Franç. Géotech. n 48, pp. $15-34$ (juillet 1989)

\section{Résumé}

Cet article passe d'abord en revue les différents essais vraie grandeur qui ont été ou peuvent être réalisés en géotechnique afin d'examiner ceux qui se prêtent à des expériences sur modèle réduit en centrifugeuse. Puis la discussion est centrée sur les relations de similitude et les conditions nécessaires pour obtenir la similitude des comportements du modèle et du prototype. A partir de postulats sur le modèle rhéologique Camclay, une méthode est proposée afin que des modèles réduits à $1 \mathrm{~g}$ puissent représenter correctement le comportement d'un problème prototype.

\footnotetext{
Abstract

This paper first makes a review of the different full-scale geotechnical tests that can be or have been carried out in order to examine which of them are appropriate for centrifuge experiments. Then the discussion is centered on scaling relations and requirements for similarity of model and prototype behaviour. From postulates based on the Camclay rheological model, a method is proposed by which $1 \mathrm{~g}$ reduced scale model tests may represent properly the behaviour of prototype problems.
} 


\section{INTRODUCTION}

Les centrifugeuses sont utilisées dans la recherche en géotechnique depuis maintenant soixante ans, et de façon intensive depuis quinze à vingt ans. Les centrifugeuses deviennent de plus en plus courantes. La technique semble avoir été acceptée par la communauté si l'on se réfère à la prolifération de machines dans tous les pays. Il est probable que nous serons noyés d'ici une décade sous les communications sur travaux en centrifugeuse en géotechnique, comme nous avons été submergés, à différentes époques de l'histoire de la mécanique des sols, par des articles sur la capacité portante, sur les pieux et plus récemment, sur les lois constitutives dans les sols. Nombre de petites (rayon inférieur à $1 \mathrm{~m}$ ), moyennes (rayon de l'ordre de $2 \mathrm{~m}$ ) et de grandes (rayon supérieur à $3 \mathrm{~m}$ ) centrifugeuses ont été construites en Europe, au Japon et aux Etats-Unis, à la suite des développements menés initialement en Grande-Bretagne et en Union-Soviétique. Il faut s'attendre à une compétition croissante pour fournir du travail à ces centrifugeuses.

Dans ces conditions, il semble opportun d'examiner la philosophie de la modélisation géotechnique en centrifugeuse, les applications qui en sont faites, ainsi que la pertinence des relations de similitude appliquées aux modélisations à $1 \mathrm{~g}$ et en centrifugeuse. On essayera d'abord ici de classer les problèmes qui se présentent au géotechnicien du point de vue de leur aptitude à être étudiés par modèle physique. Puis on passera en revue les relations de similitude, et enfin, on examinera l'application à la prévision du comportement des ouvrages prototypes, de résultats d'essais sur modèles réduits effectués à $1 \mathrm{~g}$ et sous niveau de $\mathrm{g}$ plus élevé.

\section{LES CLASSES DE PROBLÈMES SUR SITES}

En premier lieu, nous considérerons les divers essais prototypes ou grandeur réelle qui peuvent être ou ont été effectués pour déterminer ceux qui sont appropriés pour des expériences en centrifugeuse. Ces essais ont été classés par ordre croissant de complexité, bien que ceci soit, dans une certaine mesure, affaire d'opinion. La liste ne prétend pas être exhaustive. Les essais grandeur réelle complètement instrumentés et documentés sur une structure quelle qu'elle soit, sont rares.

\subsection{Fondations avec chargement externe}

\subsubsection{Statique}

Dans ces problèmes, le chargement est appliqué relativement lentement à la structure et au sol, et l'enfoncement de la fondation est mesuré et représenté en fonction de la charge. De tels essais sont effectués pour vérifier des calculs analytiques ou par éléments finis mettant en jeu des équations différentielles ellip- tiques, pour examiner les déplacements et contraintes dans le milieu. Vers la fin du chargement, quand la «rupture » de la fondation est imminente, les résultats des essais sont comparés avec les théories de capacité portante qui comportent des équations différentielles hyperboliques. En général, ces essais se veulent indépendants du temps, si bien qu'ils seront effectués avec une vitesse de chargement appropriée au type de sol selon qu'il s'agisse de sables secs ou saturés ou d'argiles.

\section{Semelles sur ou proche de la surface du sol}

Les essais prototypes les plus faciles à réaliser à une taille proche de la grandeur réelle sont peut être lapplication d'un effort axial incliné, excentré ou latéral, à une fondation ou une semelle placée à la surface du sol ou légèrement encastrée. Ces essais portent sur des fondations de géométrie quelconque: filante, carrée, circulaire, etc. Le sol dans les essais de semelles ou de pieux est normalement dans son état naturel.

\section{Charges d'essieux sur les chaussées}

Si l'essieu se déplace lentement, pour qu'il n'y ait pas d'effet dynamique ou d'inertie dans la réponse de la chaussée, alors la charge peut être considérée comme statique transitoire. L'essai est pour l'essentiel similaire au chargement d'une fondation, exception faite de la nature déformable de la roue et de la géométrie particulière intervenant dans l'interaction chaussée/sol support. L'attention est ici portée à des aspects différents de la capacité portante habituelle, car ce qui intéresse l'ingénieur routier c'est la rupture, dans le sens restreint de la détérioration de la chaussée, c'està-dire un problème de déformations plastiques excessives. Les chaussées reposent à la fois sur des sols naturels et des sols reconstitués.

Tous les essais précédents peuvent être menés en prenant en considération l'influence du temps. Le sable (le sable comme l'argile peuvent être gelés dans le cas de construction en Arctique) peut fluer sous charge constante, en particulier sous des charges voisines de la rupture pour une fondation. On peut encore maintenir longtemps le chargement d'argiles et suivre leur tassement au cours du temps.

Pour aucun de ces essais, qu'ils soient ou non dépendants du temps, on ne peut tester des fondations très grandes ou appliquer des charges très importantes en raison du coût. Un programme d'essai implique des dépenses d'installation, d'instrumentation, d'essais, d'acquisition de données et d'étude devenant d'un coût rapidement prohibitif avec la taille. Pour cette raison, avec les structures offshore, qui mettent en jeu de très grands pieux, avec des diamètres de $1,2 \mathrm{~m}$ ou plus et des longueurs approchant $150 \mathrm{~m}$, la conception n'est jamais basée sur le résultat d'essais vraie grandeur. Les méthodes de calcul se fondent sur une extrapolation de résultats d'essais sur pieux beaucoup plus petits, de moins de $30 \mathrm{~m}$ de longueur et de quelques dizaines de centimètres de diamètre. Comme on le sait, des essais de chargement de pieux isolés, en offshore, nécessitant des charges de 2-300 $000 \mathrm{kN}$ 
n'ont jamais été effectués et sont peu probables dans le futur au vu des conditions économiques dans le monde pour le pétrole. Probablement le premier essai en vraie grandeur de ce type sera fait lorsqu'une plateforme sera affectée par une rupture de fondation.

\subsubsection{Dynamique}

Tous les essais décrits plus haut peuvent, bien sûr, être effectués sous chargement dynamique mais ces cas sont moins nombreux que les essais de chargement statique. Il en est rarement rendu compte dans la littérature, peut être en raison du nombre limité de situations réelles où le comportement de fondations sous charge dynamique a posé problème. Les facteurs de sécurité des fondations sous chargement statique sont en général si élevés (probablement de l'ordre de 6 à 10) que les charges dynamiques transitoires dues, par exemple, aux séismes, ne conduisent pas les fondations à une charge proche de la rupture si l'on excepte des conditions exceptionnelles comme celles ayant affecté une ou deux structures à Mexico en septembre 1985. A moins que le sol ne change de propriétés par liquéfaction, ou comme résultat de déformations cumulées sous un nombre important de cycles de contrainte élevée, la rupture de fondation sous condition dynamique paraît exceptionnelle. Pourtant des essais sur site de ce type ne sont pas spécialement difficiles à effectuer, au moins sur des fondations de petite taille et à faible niveau de chargement; ils seraient une source importante d'information et de connaissances sur les propriétés dynamiques des sols et sur l'interaction sol-structure pour la simulation en centrifugeuse ou par d'autres techniques.

\subsection{Excavation et remblaiement (chargement pondéral intrinsèque)}

Dans les essais décrits dans la partie précédente, le chargement est externe et est créé lors de l'expérimentation. Dans le cas présent, une situation courante en géotechnique est celle où le chargement est dû au matériau lui-même sous l'effet de la gravité. Les contraintes et déformations sont le résultat de l'effet de la masse des matériaux dans un environnement de pesanteur et de conditions aux limites imposées. Les structures mettant en jeu ce type de chargement incluent barrages, remblais, excavations, tranchées, déblais, etc.

\subsubsection{Statique}

Il est un peu difficile en pratique de séparer processus dépendants et indépendants du temps dans la réponse de telles structures, qui ont généralement une durée de vie longue; mais, par commodité nous discuterons séparemment ces deux aspects. Considérant d'abord les comportements indépendants du temps, la classification est la suivante:

Excavations, murs ancrés et rideaux de palplanches. Le trait commun à ces constructions est que l'excavation a été faite et l'ouvrage est réalisé dans les sols en place et dans leur état naturel.

Remblais, barrages et murs de soutènement. Ces ouvrages sont réalisés avec des matériaux de construction qui sont des sols naturels remaniés et retraités par l'excavation, le transport et la mise en place.
Tunnels et puits verticaux. Les excavations situées entièrement sous la surface du terrain naturel constituent une catégorie spéciale, qui pourrait être rattachée au premier groupe, mais qui requiert un traitement particulier dans les essais sur modèle. Dans ces situations, le sol est déjà contraint sous la pesanteur, et les efforts sur la structure (revêtement du tunnel ou du puits) sont dus à un enlèvement de sol pour créer une cavité dans le milieu continu. Les contraintes et déplacements autour de la cavité se développent de manière tridimensionnelle à mesure que la cavité progresse mais se réduiront éventuellement à un problème bidimensionnel quand le tunnel ou le puits sera plus long. Autour de la base d'un puits vertical, les conditions de contraintes sont bien sûr, tridimensionnelles. Dans les tunnels profonds, le champ de contraintes induit par la gravité est relativement uniforme devant les dimensions du tunnel.

La dépendance en fonction du temps du comportement des structures citées dans cette partie peut être généralement séparée en deux aspects: l'aspect consolidation avec dissipation des pressions interstitielles, et le fluage. La question de la consolidation est bien comprise. En revanche, les processus de fluage n'ont pas été étudiés aussi en détail, bien qu'ils représentent un facteur important de modification des contraintes dans le cas des écrans de soutènement ancrés et des tunnels pour lesquels le changement des contraintes s'établit sur des périodes de temps relativement longues.

\subsubsection{Dynamique}

Toutes les structures décrites ci-dessus peuvent être soumises à des sollicitations dynamiques dues à des explosions, des séismes, mais les effets principaux du point de vue de l'ingénieur sont souvent restreints aux constructions au-dessus du sol. Les effets des séismes sur les tunnels paraissent moins sévères que sur les structures en surface. Dans les matériaux secs ou partiellement saturés ou dans les sols granulaires plus fins totalement saturés des déplacements excessifs, voire la rupture, peuvent résulter d'une sollicitation dynamique. Avec les argiles, la dégradation du comportement du sol sous cycles de chargement peut être importante. Cependant, il est bien connu qu'avec les sables saturés, la préoccupation principale pour la plupart des structures sous excitation sismique ou sous choc, c'est la possibilité de liquéfaction.

\subsection{Pénétration}

Une catégorie différente d'essais sur site regroupe les situations où le processus implique un passage de la surface en profondeur et pour lesquelles les effets de surface sont minimes. Les fondations profondes, les essais de pénétration, les pieux et les ancrages entrent dans cette catégorie.

\subsubsection{Statique}

SPT, CPT, pieux, ancrages. Au stade de la reconnaissance, des essais statiques peuvent comprendre des profils au pénétromètre (CPT) avec lequel une 
petite pointe conique est foncée dans le sol relativement lentement, tandis que l'on mesure la résistance sous la pointe du cône et le frottement sur un manchon.

L'essai de chargement statique est généralement effectué sur les pieux après dissipation des pressions interstitielles provoquées par le battage. Des pieux de 20 à $30 \mathrm{~m}$ de longueur sont fréquemment testés sous charge axiale, mais souvent, seuls la charge appliquée et le déplacement de la tête sont mesurés. Des pieux plus grands ou des caissons, et en particulier les très grands pieux en offshore et les groupes de pieux ne peuvent pas être testés. La même observation s'applique à certains ancrages, et aux radiers fortement encastrés.

Le phénomène dépendant du temps qui suit la pénétration du cône dans les sables saturés et argiles peut être suivi si le cône est équipé d'un capteur de mesure de pression fluide. Les pieux n'exhibent pas en général de tassement important sous charge maintenue et les effets de consolidation, fonction du temps, sont de ce fait négligés si l'on excepte le phénomène de cicatrisation. En revanche, les pieux dans les sols gelés sont sujets au fluage, et il doit en être tenu compte dans la conception des pieux en sol gelé.

\subsubsection{Dynamique}

Des conditions dynamiques prévalent dans de nombreux problèmes de cette catégorie. A l'échelle la plus petite, on trouve l'essai SPT. Beaucoup d'études ont été faites sur l'aspect dynamique de cet essai de pénétration et sur son effet sur le nombre de coups. En raison de la taille réduite de l'équipement, de telles études peuvent être conduites dans de grandes cuves en laboratoire ou sur site dans un milieu assez uniforme. Pour les pieux battus, l'aspect dynamique de l'interaction sol-pieu a focalisé une attention considérable en raison de la perspective d'obtenir la résistance statique à l'enfoncement du pieu à partir de mesures appropriées lors du battage.

Explosions, cratères. Un autre volet du comportement dynamique des sols sont les applications généralement militaires, des phénomènes de pénétration et d'explosion. Dans le cas de la pénétration, le sujet est celui de la distance sur laquelle un projectile peut pénétrer dans le sol. Avec des bombes et des missiles, le cratère ou la cavité formés dans le sol par l'explosion qui suit est un problème d'intérêt considérable. Les aspects importants sont l'effet de la taille et de la position de la charge explosive, et des propriétés du sol sur le diamètre et la profondeur du cratère de la cavité. Ces événements explosifs s'accompagnent d'effets transitoires de longue durée impliquant la dissipation des pressions interstitielles, l'éboulement des parois du cratère et des changements de propriétés dans les sols adjacents. Peu d'attention a été accordée à ces phénomènes jusqu'à présent.

Pour la Défense, les effets des explosions sur les structures enterrées ou en surface sont très importants, ce qui explique que l'intensité et l'évolution dans le temps de la sollicitation frappant une structure aient, elles, été étudiées.

\section{MODÉLISATION DES CONDITIONS DE SOL}

Pour la construction de modèles, des matériaux différents demandent à être traités différemment, quelle que soit l'échelle, en centrifugeuse ou non. On discute ici brièvement des différents matériaux géotechniques et des difficultés associées à leur modélisation. Dans quelques circonstances impliquant ou non des essais en centrifugeuse, certaines des propriétés devront être représentées à l'échelle, alors le matériau réel ne pourra pas être utilisé.

\subsection{Sable}

Il n'est généralement pas difficile de préparer en laboratoire du sable dans un état uniforme de densité relative prédéterminée alors qu'aucun sable ne peut être prélevé dans des conditions non perturbées pour l'utiliser dans un modèle. Des questions essentielles se posent sur la structure du sol obtenu.

Un intérêt particulier a été porté au développement de l'anisotropie dans les dépôts de sable naturels et reconstitués, et sur l'effet d'une telle anisotropie sur les propriétés du matériau. La simulation de conditions en place anisotropes particulières est difficile sinon impossible en raison même du problème de caractérisation de l'anisotropie. Quelquefois, le sable apparaît être partiellement cimenté du fait du temps ou d'effets chimiques; la modélisation d'une telle cimentation soulève aussi certaines difficultés. Cependant, une cimentation artificielle utilisant du ciment Portland ou du plâtre de Paris peut être envisagée. Notons enfin les difficultés attachées à la construction de remblais en sable (effets de Coriolis) ou d'excavations, dans la centrifugeuse en cours de rotation.

\subsection{Argile}

Bien qu'un bloc d'argile pratiquement non remanié puisse être prélevé sur site, il représente les propriétés de l'argile sur un échantillon de très petites dimensions. Un modèle construit à partir de lui ne peut donc pas simuler les propriétés à l'échelle de l'ensemble du site prototype. Le sol prototype, qu'il soit normalement ou surconsolidé, doit ainsi être modélisé pour un essai à l'échelle réduite. Un profil d'argile normalement consolidée, peut être obtenu en laboratoire ou en centrifugeuse à partir d'un matériau préparé à une teneur en eau voisine de la limite de liquidité. De tels spécimens sont, bien sûr, toujours remaniés. En laboratoire la reproduction d'un profil normalement consolidé est plus difficile et l'argile sera en général consolidée par couches, dans une presse, à différents niveaux, puis réassemblée. La consolidation peut être obtenue en utilisant le gradient hydraulique et les forces de masse associées pour obtenir un champ de pesanteur artificiel. Dans les deux cas, un temps important est nécessaire pour obtenir l'état consolidé recherché sur toute l'épaisseur du profil de sol. Un profil normalement consolidé n'est pas souhaitable pour les expériences comportant des structures en surface car l'argile a une résistance nulle à ce niveau. Dès lors toute structure posée en surface subira de 
grands tassements dus aux déformations plastiques du matériau extremement souple sur lequel il repose. Dans de tels essais, il est souhaitable d'avoir un matériau légèrement surconsolidé ce qui peut être obtenu par addition d'un chargement de surface, que l'on enlèvera après, pour fournir la résistance de surface cherchée.

Si l'argile est surconsolidée avec une valeur à peu près uniforme sur l'épaisseur, alors les procédures de modélisation à une échelle quelconque sont directes. Un échantillon peut être consolidé en laboratoire dans une presse. $\mathrm{Si}$, au contraire, l'argile est surconsolidée avec un profil de résistance compliqué résultant de la dessication ou d'autres effets, la préparation du modèle sera difficile. On peut envisager alors une consolidation par couches en laboratoire, sous presse. puis l'assemblage des différentes couches de matériaux pour former le modèle.

\subsection{Roche}

La structure, qu'elle soit naturelle ou faite par lhomme, peut avoir des dimensions trop importantes pour être modélisée sur la centrifugeuse, sans qu'il faille aussi reproduire à l'échelle les propriétés de la roche. On doit alors fabriquer un matériau complètement artificiel. A l'évidence, des difficultés se présentent ici pour la caractérisation du comportement de la roche réelle et de la roche modèle, de même en ce qui concerne la construction du matériau artificiel pour avoir une similitude de comportement correcte.

\subsection{Sols-structures}

Les structures considérées dans le chapitre *Classes de problèmes sur sites" où le sol réel était modifié par excavation ou remanié pour former des remblais ou des barrages présentent des problèmes particuliers de modèlisation. Les conditions initiales avant application des charges ultérieures (que celles-ci résultent d'un accroissement de $\mathrm{g}$ ou de constructions en surface après excavation ou construction de remblais) dépendent entièrement du processus et de l'historique de la construction. Il est clair, dans ces cas, que la construction du modèle doit simuler d'aussi près que possible le processus adopté pour le prototype. Dans la centrifugeuse ceci est difficile mais peut être obtenu en construisant le remblai ou en creusant l'excavation en cours de rotation. S'il y a dissipation de pressions interstitielles et consolidation, il faut porter attention à l'échelle de temps de la construction dans la centrifugeuse; des temps importants peuvent être alors requis.

Comme un ancrage doit être enfoui dans le sol, sa relation effort-déplacement dépendra aussi probablement du processus d'excavation et de remblaiement et devra être représenté dans le modèle. Ces effets seront moins importants si l'on s'intéresse uniquement aux efforts de rupture. L'état de contrainte autour d'un pieu réel dépend lui du processus de battage, qui devrait être simulé correctement dans un essai sur modèle réduit. Les études sur modèle effectuées sans porter attention aux relations de similitude ont mon- tré que la loi effort-déplacement d'un groupe de pieux dépend de l'ordre dans lequel les pieux sont battus. Une simulation correcte du battage des pieux et de la séquence de battage dans un groupe apparaît difficile à simuler correctement dans des essais en centrifugeuse.

\subsection{Conditions spéciales}

On rencontre un problème particulier dans les études sur modèle lorsque le comportement du milieu prototype est affecté ou constitué entièrement de discontinuités (à l'exception des discontinuités entre grains individuels dans un milieu granulaire). Dans des argiles fracturées ou fissurées et dans des masses rocheuses existent fréquemment des réseaux complexes de discontinuités qui ont des effets importants sur les champs de déplacements et de contraintes qui se développent dans le milieu lorsqu'on applique un effort. Dans de nombreux matériaux géologiques, la rupture se produit comme le résultat d'un cisaillement le long de lentilles minces ou de surfaces de rupture. Ceci soulève des questions quant à la simulation correcte sur modèle réduit du développement de tels phénomènes. Il semble à l'heure actuelle très difficile de produire des modèles de structures réelles ayant un tel comportement de fracturation ou de rupture. Une application reste peut-être la vérification de codes de calcul conçus pour traiter de telles difficultés. Dans ce cas les essais sur modèles ne prétendent pas simuler un prototype particulier mais plutôt un prototype général ou idéal qui est l'objet de l'étude analytique.

Ces considérations sont résumées dans le tableau 1.

\section{LES RELATIONS DE SIMILITUDE}

Beaucoup de choses ont été écrites à propos des relations de similitudes applicables aux essais en centrifugeuse (6). Les éléments donnés ci-dessous reproduisent certains développements traditionnels des équations, pour aboutir aux conditions nécessaires pour une similitude correcte pour des essais effectués à un niveau de $\mathrm{g}$ et une échelle quelconques. Les relations de similitude peuvent être établies de différentes façons, par exemple par l'analyse dimensionnelle, ou en considérant les équations décrivant la réponse du matériau aux charges appliquées. Nous suivrons ici la dernière approche.

Les équations d'équilibre dynamique ont la forme générale:

$$
\frac{\partial \tau_{i, j}}{\partial x_{j}}+f_{i}=\rho u_{i, t t}
$$

où $\tau$ représente les contraintes, $\mathrm{f}$ les forces de volume par unité de volume, $\rho$ la densité et u le déplacement.

Une composante de cet ensemble est:

$$
\frac{\partial \tau_{11}}{\partial \mathrm{x}_{1}}+\frac{\partial \tau_{12}}{\partial \mathrm{x}_{2}}+\frac{\partial \tau_{13}}{\partial \mathrm{x}_{3}}+\mathrm{f}_{1}=\frac{\partial^{2} \mathrm{u}_{1}}{\partial \mathrm{t}^{2}}
$$


Tableau 1 - Essais prototypes et considérations sur la modélisation Table 1 - Prototype tests and modelling considerations

\begin{tabular}{|c|c|c|c|}
\hline \multirow{2}{*}{ Essais grandeur réelle } & \multicolumn{3}{|c|}{$\begin{array}{l}\text { Possibilités de simulation des matériaux } \\
\text { pour des essais à échelle réduite }\end{array}$} \\
\hline & Matériaux naturels & Remaniés & Préoccupations \\
\hline $\begin{array}{l}\text { Fondations avec charges exté- } \\
\text { rieures } \\
\text { fondations superficielles } \\
\text { essieu }\end{array}$ & \multirow{4}{*}{$\begin{array}{l}\text { impossible } \\
\text { en toutes } \\
\text { circonstances }\end{array}$} & même matériau & $\begin{array}{l}\text { densité, consolidation, vieillisse- } \\
\text { ment, cimentation, anisotropie, } \\
\text { taille des grains }\end{array}$ \\
\hline $\begin{array}{l}\text { Chargement gravitaire, remblai, } \\
\text { barrages, murs de soutènement, } \\
\text { puits, tunnels }\end{array}$ & & même matériau & $\begin{array}{l}\text { comme ci-dessus, et installation } \\
\text { ou excavation en cours de rota- } \\
\text { tion }\end{array}$ \\
\hline $\begin{array}{l}\text { Fondations profondes, pieux, } \\
\text { groupes de pieux (statique) SPT, } \\
\text { CPT (dynamique), pieu, battage } \\
\text { (dynamique) } \\
\text { Explosions (dynamique), réponse } \\
\text { sismique (dynamique) toutes } \\
\text { structures }\end{array}$ & & $\begin{array}{l}\text { même matériau } \\
\text { peut-être } \\
\text { même matériau }\end{array}$ & $\begin{array}{l}\text { comme au-dessus } \\
\text { taille des grains, effets de Corio- } \\
\text { lis, petits détails }\end{array}$ \\
\hline $\begin{array}{l}\text { Très grandes échelles, barrage, } \\
\text { plate-forme pétrolière offshore, } \\
\text { centrale nucléaire } \\
\text { Glissement de terrain, coulées, } \\
\text { structures géologiques, tectoni- } \\
\text { que des plaques, dômes de sel, } \\
\text { faille }\end{array}$ & & $\begin{array}{l}\text { même matériau } \\
\text { matériau artificiel }\end{array}$ & $\begin{array}{l}\text { propriétés des matériaux réels et } \\
\text { artificiels, joints, fractures, espa- } \\
\text { cement, petites constructions et } \\
\text { détails géologiques }\end{array}$ \\
\hline
\end{tabular}

qui peut être écrite avec les valeurs relatives au prototype en ajoutant l'indice p aux différents termes, ainsi $\tau_{12 p}, x_{1 p}, t_{p}$, etc. Si les quantités prototypes sont exprimées à laide des facteurs d'échelle adimensionnels $\tau^{*}, x^{*}, t^{*}$, etc., multipliés par les quantités afférant au modèle, l'équation d'équilibre du prototype (2) peut être réécrite en quantités du modèle:

$$
\begin{aligned}
& \frac{\tau^{*}}{x^{*}}\left[\frac{\partial \tau_{11 m}}{\partial x_{1 m}}+\ldots\right]+f^{*} f_{1 m} \\
& =\rho^{*} \rho_{m} \frac{x^{*} \partial^{2} u_{1 m}}{\left(t^{*}\right)^{2} \partial t_{m}^{2}}
\end{aligned}
$$

ou

$$
\begin{aligned}
& {\left[\frac{\partial \tau_{11 \mathrm{~m}}}{\partial \mathrm{x}_{1 \mathrm{~m}}}+\ldots\right]+\frac{\mathrm{f}^{*} \mathrm{x}^{*}}{\tau^{*}} \mathrm{f}_{1 \mathrm{~m}}} \\
& =\frac{\rho^{*}\left(\mathrm{x}^{*}\right)^{2}}{\tau^{*}\left(\mathrm{t}^{*}\right)^{2}} \frac{\partial^{2} \mathrm{u}_{\mathrm{m}}}{\partial \mathrm{t}_{\mathrm{m}}^{2}}
\end{aligned}
$$

où $\tau^{*}$ est le rapport de la contrainte dans le prototype à celle dans le modèle en des points homologues, $\mathrm{x}^{*}$ est le facteur d'échelle des longueurs et $\mathrm{t}^{*}$ est le facteur d'échelle du temps, etc.

Comme les éléments du modèle doivent être aussi en équilibre dynamique, en écrivant une équation identique à (2) mais avec des indices $\mathrm{m}$, cette condition d'équilibre est satisfaite si:

$$
\frac{f^{*} x^{*}}{\tau^{*}}=1
$$

et

$$
\frac{\rho^{*}\left(\mathrm{x}^{*}\right)^{2}}{\tau^{*}\left(\mathrm{t}^{*}\right)^{2}}=1
$$

Dans les problèmes statiques, seule la relation (5) intervient. En général, dans les problèmes géotechniques, $f_{j}$ sont des forces de masse dues à la gravité et peuvent être écrites:

$$
\mathrm{f}_{\mathrm{j}}=\rho \mathrm{g}_{\mathrm{j}}
$$

où $g_{j}$ sont les composantes de l'accélération gravitationnelle. Dans le repère choisi, habituellement, l'une de ces directions est prise selon la verticale et $\mathrm{g}$ est alors simplement l'accélération de la pesanteur. En considérant (7) pour le prototype et le modèle, la relation de similitude (5) devient:

$$
\frac{\rho^{*} \mathrm{~g}^{*} \mathrm{x}^{*}}{\tau^{*}}=1
$$

Ces relations sont valables quelle que soit la nature ou le comportement des matériaux du modèle, et du prototype (solide, liquide, gaz). Ainsi, avant de discuter les équations (6) et (8) plus loin, il y a une autre condition qui doit être satisfaite - les relations de comportement entre modèle et prototype doivent être accordées. Si par exemple, le modèle et le matériau ont un comportement élastique linéaire, la relation constitutive est de la forme:

$$
\epsilon_{11}=\frac{1}{E}\left[\tau_{11}-\nu\left(\tau_{22}+\tau_{33}\right)\right]
$$


Comme plus haut, ceci peut être écrit pour le prototype et modifié pour le modèle afin d'obtenir la condition de similitude (comme les déformations sont sans dimension).

$$
\frac{\tau^{*}}{E^{*}}=1
$$

Le coefficient de Poisson doit être le même dans le modèle et dans le prototype car c'est une grandeur adimensionnelle. Le résultat, équation (10), pourrait aussi avoir été établi par l'analyse dimensionnelle ou en considérant que $\mathrm{E}$ a les dimensions d'une contrainte. Les sols ne sont pas, bien sûr, élastiques linéaires, et sont décrits par des relations plus complexes. Le modèle le plus simple est basé sur l'hypothèse d'état critique, comme utilisée, par exemple, par ROSCOE et BURLAND. Le modèle Camclay s'appuie sur la théorie élastoplastique incrémentale si bien qu'outre les conditions d'équilibre précédentes, le modèle nécessite la donnée d'une surface de charge, d'une règle d'écoulement, et d'une loi d'écrouissage. $\mathrm{Ce}$ modèle peut être pris comme exemple pour établir les relations de similitude.

La surface de charge est elliptique, elle doit avoir la même forme pour le prototype et le modèle. Elle est exprimée habituellement par:

$$
q^{2}-M\left(p p_{c}-p^{2}\right)=0
$$

où q est la contrainte de cisaillement, $\left(\tau_{11}-\tau_{33}\right) / 2$, $p$ est la composante hydrostatique en contraintes effectives, $\left(\tau_{11}^{\prime}+2 \tau_{33}^{\prime} / 3\right.$, M est une constante sans dimension, et $\mathrm{p}_{c}$ est la valeur de $\mathrm{p}$ à l'intersection de l'ellipse et de l'axe des p. A l'évidence p doit être le même dans le prototype et le modèle, et p, et $\mathrm{q}$, étant des contraintes, doivent satisfaire aux relations de similitude exprimées par l'équation (8).

La loi d'écrouissage dans le modèle Camclay prend en compte la variation de volume du matériau, dans un état normalement consolidé. Ceci est simplifié dans le modèle sous la forme d'une relation linéaire entre un volume spécifique adimensionnel v $(1+e$ où $e$ est l'indice des vides) et le logarithme de la contrainte hydrostatique effective, p normalisée par une contrainte unité. Cette droite est définie par sa pente $\lambda$ (adimensionnelle) et par un volume spécifique pris habituellement égal à la valeur $v_{1}$ pour $\mathrm{p}=1$. Le déchargement à partir d'une contrainte $\mathrm{p}_{c}$ est aussi approximé par une droite dans l'espace $v$-logp, de pente adimensionnelle $\kappa$. Les déformations dans le sol sont prises comme la somme des composantes élastique et plastique. Les déformations volumiques élastiques sont non linéaires mais réversibles, et sont décrites par $\kappa$, alors que les distorsions élastiques sont supposées linéaires dans une version du modèle et sont décrites avec le module de cisaillement G.

Les déformations plastiques incrémentales sont généralement calculées en utilisant une loi d'écoulement associée, bien qu'une loi non associée puisse être utilisée. Avec la loi d'écoulement, la direction du vecteur incrément de déformation plastique (PSIV) est rapportée à la normale à la surface de charge dans lespace des contraintes, au point de contrainte considérée. C'est l'angle entre PSIV et la normale qui caractérise le degré de non-associativité: un angle nul correspond à une loi associée ou normale; des angles différents de zéro sont employés avec une loi d'écoulement non associée.

Un sol qui a été chargé jusqu'à une certaine valeur de la contrainte effective hydrostatique $p_{c}$ puis déchargé jusqu'à une contrainte $\mathrm{p}_{1}$ est caractérisé par le rapport (adimensionnel) $\mathrm{p}_{c} / \mathrm{p}_{1}$ appelé rapport de surconsolidation (OCR). Si OCR égal 1, le sol est normalement consolidé.

Il est fait l'hypothèse, dans la théorie d'état critique, qu'un sol, soumis à des contraintes de cisaillement, atteindra éventuellement un état critique où les déformations se développent à vitesse constante, pour une valeur de volume spécifique reliée à la contrainte effective hydrostatique. A cet état, la relation entre contrainte de cisaillement, volume spécifique, et contrainte hydrostatique (dans l'espace q - v - logp) est une courbe dont la projection est une doite dans le plan v - logp. Cette ligne droite est appelée ligne d'état critique et est supposée être parallèle et sous la droite d'état normalement consolidé.

Dans les essais sur modèles réduits utilisant un matériau Camclay, il suit que le sol du modèle doit avoir les mêmes caractéristiques de changement de volume que le prototype (lui-même de type Camclay) en raison des constantes adimensionnelles intervenant, bien que la réponse du matériau du modèle puisse correspondre à un intervalle différent de la droite du plan v-logp. Quelle que soit la loi d'écoulement qui s'applique au prototype, celle-ci doit être aussi applicable au modèle, parce que la règle est représentée par un angle, quantité adimensionnelle. Une autre des conséquences du modèle Camclay est que deux sols, possédant les mêmes caractéristiques $\lambda$, $\kappa$ et $v_{1}$ et ayant la même valeur de OCR, même s'ils ont subi des pressions maximales $p_{c}$ différentes, exhiberont des comportements contrainte-déformation similaires quand ils sont soumis à des chemins de contraintes semblables. Les contraintes sur les deux courbes contrainte-déformation diffèreront pour des déformations identiques seulement dans le rapport des deux pressions de préconsolidation.

Cette similitude supposée pour le comportement en cisaillement, ce qui inclut les déformations élastiques, a des conséquences pour le module de cisaillement du matériau du modẻle réduit, qui doit suivre la règle de similitude (8) pour le facteur d'échelle des contraintes $\tau^{*}$, parce que $\mathrm{G}$ a les dimensions d'une contrainte. On doit noter ici que le module de déformation volumique $\mathrm{K}$ est non linéaire parce que $K$ est constant dans une représentation semi-logarithmique, avec:

$$
v=v_{c}-\kappa \log \frac{p}{p_{c}}
$$

La déformation volumique $\mathrm{d} \epsilon_{\mathrm{v}}$ est donnée par:

$$
\mathrm{d} \epsilon_{\mathrm{v}}=\frac{\kappa}{\mathrm{pv}} \mathrm{dp}
$$

en considérant les déformations de compression comme positives. Cependant, la déformation volumique est aussi définie par: 


$$
\mathrm{d} \epsilon_{\mathrm{v}}=\frac{\mathrm{dp}}{\mathrm{K}}
$$

si bien que $\mathrm{K}$ devient une fonction de la pression $\mathrm{p}$ :

$$
\mathrm{K}=\frac{\mathrm{pv}}{\mathrm{K}}
$$

comme $\kappa$ est petit le changement de $v$ avec $p$ est aussi petit, et $\mathrm{K}$ est donc presque linéaire avec $\mathrm{p}$.

\subsection{Essais sur modèle réduit}

Pour des essais statiques qui tendent à simuler un prototype réel ou hypothétique, les relations de similitude sont données par l'équation (8). En général, pour les matériaux du génie civil, incluant les sols, la densité du matériau du modèle réduit est presque la même que celle du prototype. En effet il est difficile de la rendre très différente, tout en conservant les propriétés souhaitées. Comme il est bien connu, le comportement mécanique du sol est si dépendant de facteurs comme la taille des grains, la courbe granulométrique, l'angularité, l'état de surface, etc., que sa substitution par un milieu granulaire fait de particules métalliques (pour augmenter la densité) ou de matières plastiques (pour la diminuer) donnerait des réponses très différentes sous les contraintes appliquées. Généralement, ainsi, pour les essais sur modèles réduits, le même sol ou un sol semblable à celui du prototype est utilisé. Dans ce cas $\rho^{*}$ est égal à l'unité et l'équation (8) devient:

$$
\frac{g^{*} x^{*}}{\tau^{*}}=1
$$

Des essais sur modèles réduits ont des facteurs d'échelle géométrique plus grands que 1 , habituellement dans l'intervalle 10 à 100 , bien que des valeurs plus grandes puissent être employées. Afin de produire des relations contrainte-déformation similaires, un objectif souhaitable est de reproduire les mêmes contraintes en des points homologues du prototype et du modèle réduit. Ceci implique que $\tau^{*}=1$, et donc, d'après (16) dans ce cas précis, la similitude peut seulement être obtenue si $\mathrm{g}^{*}$ et $\mathrm{x}^{*}$ sont inversement proportionnels. La conséquence en est la nécessité d'utiliser des niveaux d'accélération accrus dans les essais sur modèles réduits, ce qui a conduit au développement de centrifugeuses géotechniques. Dans le cas d'essais dynamiques sur sol sec, avec les conditions d'essai en centrifugeuse, l'équation (6) donne:

$$
t^{*}=x^{*}
$$

Ces relations de similitude sont maintenant bien connues, et généralement acceptées, tant que le prototype et le sol modèle ont des comportements similaires, bien que des questions subsistent en ce qui concerne les forts gradients de déformation dans les modèles réduits.

Comme l'expérimentation en centrifugeuse est complexe, il est apparu souhaitable d'examiner les conditions nécessaires pour obtenir une similitude correcte pour des essais sur modèles réduits effectués à $1 \mathrm{~g}$ en laboratoire. Cecî nécessite une vue différente des relations de similitude.

\subsection{Modélisation à $1 \mathrm{~g}$}

Comme on utilise le même sol ou un sol semblable dans les essais sur modèle réduit en laboratoire, $\rho^{*}$ et $\mathrm{g}^{*}$ seront égaux à l'unité dans l'équation (8) et ainsi:

$$
\tau^{*}=\mathrm{x}^{*}
$$

Ceci est obtenu dans les essais de sol à $1 \mathrm{~g}$, quand les contraintes sont produites par le poids propre du sol. Il s'en suit que les propriétés élastiques du sol, $E$ et $G$, doivent varier comme $\tau^{*}$ (ou $x^{*}$ ), c'est-à-dire, doivent dépendre de $\mathrm{p}$, la contrainte effective hydrostatique. A partir d'expériences dans lesquelles $E$ est simplement pris comme la pente initiale de la courbe contrainte-déformation d'un essai de compression au triaxial, on déduit généralement que $\mathrm{E}$ varie comme une puissance de la contrainte de confinement; typiquement 0,5 . Pour des valeurs de déformations plus grandes, un exposant égal à 1 a été proposé. Cependant, linterprétation des essais de laboratoire, pour lapplication à des essais sur modèle réduit dans lesquels les charges sont appliquées jusqu'à la rupture, devrait impliquer l'établisement d'une relation constitutive complète pour rendre compte du comportement non linéaire dissipatif du sol. Si ceci est fait, le module $\mathrm{E}$ ou $\mathrm{G}$, est simplement l'une des nombreuses constantes qui doivent être déterminées sur la base d'un meilleur ajustement du modèle à des résultats fournis par un certain nombre d'essais portant sur des géométries et des chemins de charges variables. Aucune étude de la variation de $\mathrm{E}$ avec $\mathrm{p}$ dans ces conditions n'est connue de l'auteur.

Dans le modèle Camclay, il a été montré par l'équation (15) que le modèle volumique $\mathrm{K}$ varie presque linéairement avec la pression. Comme $E$ et $G$ peuvent être exprimés en fonction de $\mathrm{K}$ et du coefficient de Poisson :

$$
\begin{aligned}
& E=3 K(1-1 \nu) \\
& G=\frac{3 K(1-2 \nu)}{2(1+\nu)}
\end{aligned}
$$

et que $\nu$ est indépendant de l'échelle, une interprétation du modèle Camclay est une dépendance linéaire de $E$ et $G$ avec la pression selon l'équation (15). La similitude des relations contrainte-déformation exhibée par des sols Camclay ayant le même OCR mais différentes valeurs de $\mathrm{pc}$ a été décrite. Par conséquent. si un sol Camclay représente à la fois des essais statiques prototypes et à échelle réduite à $1 \mathrm{~g}$, l'équation (18) sera satisfaite, et les données du modèle réduit peuvent être appliquées au prototype. Les déplacements et contraintes obtenus sur le modèle réduit doivent être multipliés par $x^{*}$ pour fournir les valeurs prototypes, les forces par $\left(x^{\circ}\right)^{3}$, moments et énergies par $\left(x^{*}\right)^{4}$, moments d'inertie (EI) par $\left(x^{*}\right)^{5}$. Dans les essais dynamiques, l'équation (6) donne:

$$
t^{*}=\left(x^{*}\right)^{0,5}
$$

si bien que les vitesses du modèle réduit doivent être multipliées par $\left(x^{*}\right)^{0.5}$ et les accélérations demeurent inchangées. Les facteurs d'échelle pour les essais en centrifugeuse et à $1 \mathrm{~g}$ sont donnés dans le tableau 2 . 
Tableau 2 - Facteurs d'échelle Table 2 - Scale factors

\begin{tabular}{|c|c|c|}
\hline Centrifugeuse & Quantité & $\begin{array}{l}\text { Modèle réduit } \\
\text { à } 1 \mathrm{~g}\end{array}$ \\
\hline$n$ & Déplacement & $n$ \\
\hline$n$ & $\begin{array}{c}\text { Temps } \\
\text { (dynamique) }\end{array}$ & $n^{0,5}$ \\
\hline 1 & Vitesse & $n^{0,5}$ \\
\hline$n^{-1}$ & Accélération & 1 \\
\hline$n^{2}$ & Force & $n^{3}$ \\
\hline$n^{3}$ & Energie, moment & $n^{4}$ \\
\hline$n^{4}$ & Moment d'inertie & $n^{5}$ \\
\hline$n^{-1}$ & Fréquence & $n^{-0,5}$ \\
\hline$n^{2}$ & $\begin{array}{c}\text { Temps } \\
\text { (consolidation) }\end{array}$ & $\begin{array}{l}n \\
{ }_{n}\end{array}{ }^{0,5} \begin{array}{l}\text { si } C_{v}=n \\
\text { si } C_{v}=n^{1.5}\end{array}$ \\
\hline
\end{tabular}

Il a été suggéré par BEEN et JEFFERIES [2] que, de façon semblable à la ligne d'état critique pour Camclay, il existait pour les sables une ligne d'état permanent «Steady State Line* (SSL) dans le plan $v-\log p$, qui a la signification suivante. Si un sable, à un certain volume spécifique (ou un indice des vides) pour une valeur particulière de $\mathrm{p}$, pour lequel le volume spécifique diffère, de la valeur donnée par la ligne SSL à la même valeur $\mathrm{p}$, d'une quantité $\Delta \mathrm{v}$ (qui peut être positive ou négative) alors le même sable, à une autre valeur de $\mathrm{p}$, aura le même comportement contrainte-déformation normalisé lorsqu'on le soumet au même trajet de charge, s'il existe un volume spécifique donnant le même $\Delta v$ à cette autre valeur de $\mathrm{p}$. Ce postulat est identique à celui décrit plus haut par ROSCOE et POOROOSHASB [16] pour le matériau Camclay. La figure 1 montre une ligne droite dans le plan e - logp, qualifiée ici de ligne d'état critique permanent et des points sur des lignes qui lui sont parallèles, pour lesquelles la condition de similitude pourrait être satisfaite. Le point à état de contrainte plus élevé est repéré par $\mathrm{P}$ (prototype); celui à l'état de contrainte plus faible $M$ (modèle). On voit que le sol du modèle est à un indice des vides plus élevé que celui du prototype. Comme le paramètre de normalisation est $\mathrm{p}$, il suit

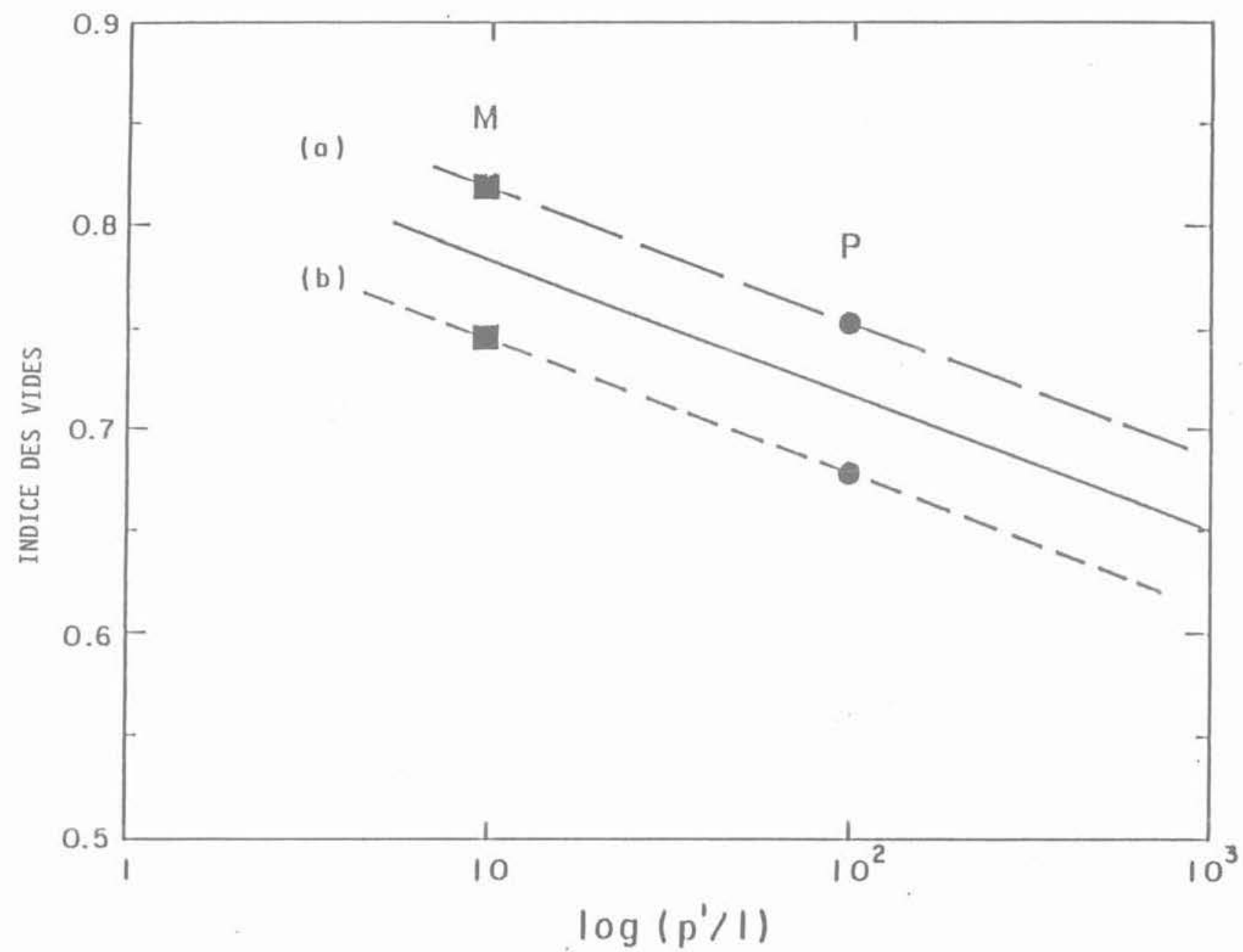

Fig. 1. - Ligne d'état critique (ligne continue) et conditions pour la similitude des relations contrainte-déplacement. P-prototype; M-modèle réduit; état de contrainte pour (a) les indices de vide plus élevés et (b) les indices de vide plus faibles que l'indice critique. Fig. 1. - Critical or steady state line (solid line) and conditions for stress-strain similarity. P-prototype; M-model stress conditions for (a) void ratios higher and (b) void ratios lower than critical. 
qu'un tel matériau satisferait les conditions de similitude pour des essais sur modèles réduits à $1 \mathrm{~g}$.

Dans les essais sur modèle effectués dans le passé, on a généralement retenu comme condition que la densité relative $\mathrm{Dr}$ devrait être la même pour le modèle réduit et le prototype. Dans la littérature, le sol modèle est décrit comme «lâche», "dense», etc., avec la conséquence que le comportement observé sera représentatif d'un sol prototype «lâche», «dense», etc. $[3,7,12,14,18]$. Cependant, il est bien connu que la relation contrainte-déformation d'un sol dépend à la fois de la densité relative et de la contrainte effective de confinement. La condition de similitude requise montrée par la figure 1 peut être évaluée comme suit.

La déformation volumique, $\epsilon_{\mathrm{v}}$, est reliée plus particulièrement à la densité relative et à la contrainte de confinement. Un sol à une densité relative quelconque se contractera, n'exhibera aucune variation de volume, ou se dilatera, selon la contrainte effective hydrostatique, p, qui lui est appliquée. Seul l'intervalle de variation de $\mathrm{p}$ change, pour ces différentes réponses en volume, lorsque la densité relative est variée. Deux ensembles typiques de courbes contrainte-déformation et déformation volumique sont présentés dans les figures 2 et 3 pour des états lâches et denses d'un même sol testé en compression triaxiale. à différentes pressions de confinement [10].
En considérant ces deux figures comme une référence, pour des essais sur modèle réduit, la question pertinente pour les conditions de similitude se pose ainsi: si le même sol est testé à deux densités relatives différentes, et à deux pressions $\mathrm{p}$ différentes de telle sorte que les relations déformation volumique fonction de la déformation axiale soient identiques, comment se compareraient les réponses contrainte de cisaillement normalisé (par p) en fonction de la déformation axiale? A partir des figures 2 et 3 et d'autres données, on a établi les courbes présentées par la figure 4 pour des essais donnant des déformations volumiques comparables (dans ce cas, proche d'une variation volumique nulle sur l'intervalle de déformations axiales développées). Il n'a pas été possible d'obtenir des données pour des comportements en déformations volumiques identiques. On voit que les courbes donnant la différence de contrainte normalisée en fonction de la déformation axiale (figure 4 b) sont raisonnablement similaires, et sont cohérentes avec les variations de déformations volumiques associées. Apparemment des comportements avec variations de volume identiques, si tant est qu'on ait pu obtenir cette situation, auraient réduit les différences entre les courbes contrainte-déformation. Ces résultats tendent à confirmer les hypothèses de similitude avancées précédemment en relation avec les lignes d'état critique et d'état permanent. Dans la figure 4,

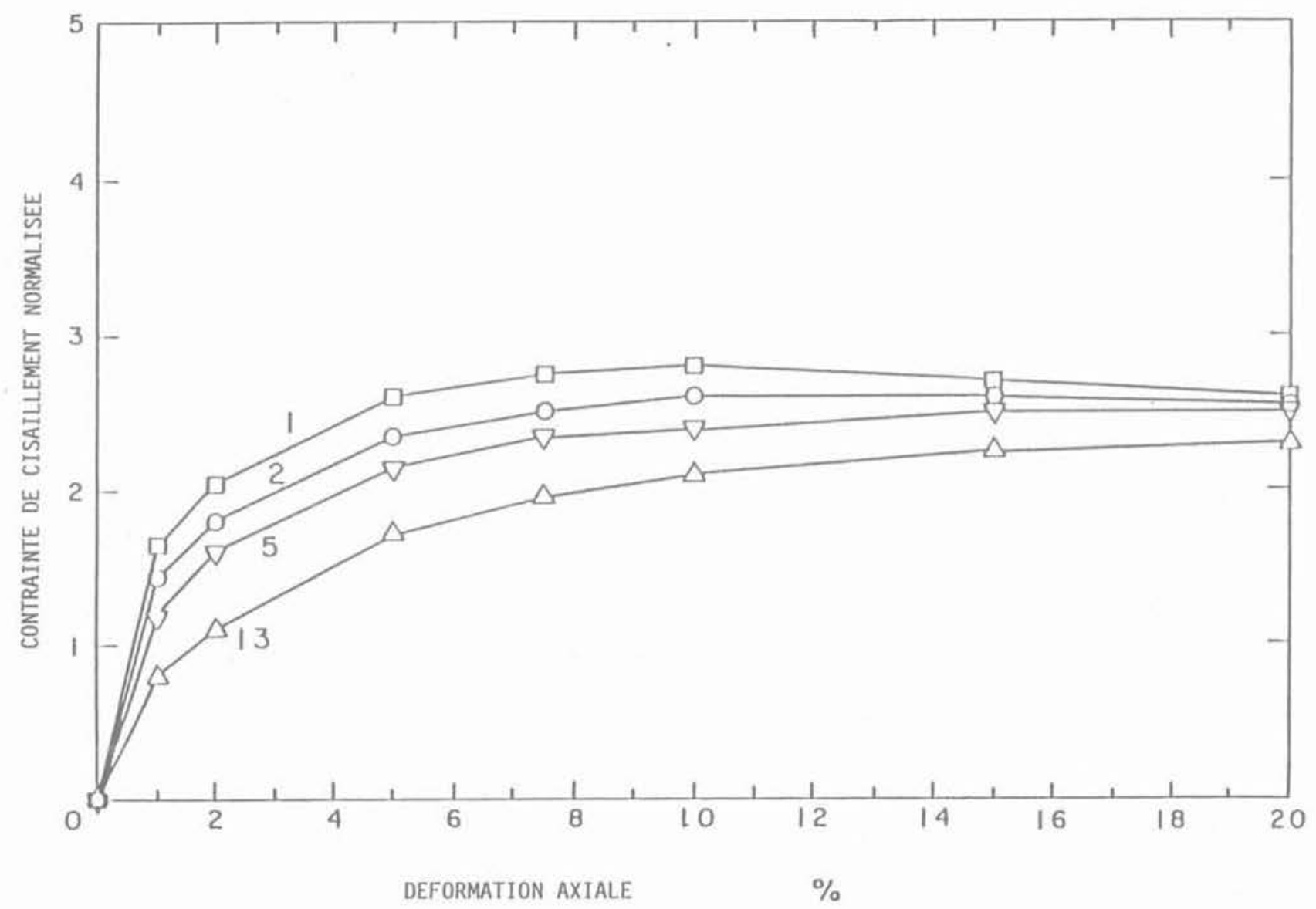

Fig. 2 a. - Courbe contrainte-déformation pour des essais de compression triaxiale (10) pour un sable lâche $\left(D_{r}=38 \%\right)$, aux pressions de confinement indiquées sur les courbes.

Fig. 2 a. - Triaxial compression test stress-strain data (10) for a loose sand $\left(D_{t}=38 \%\right)$ at confining pressures marked on the curves. 


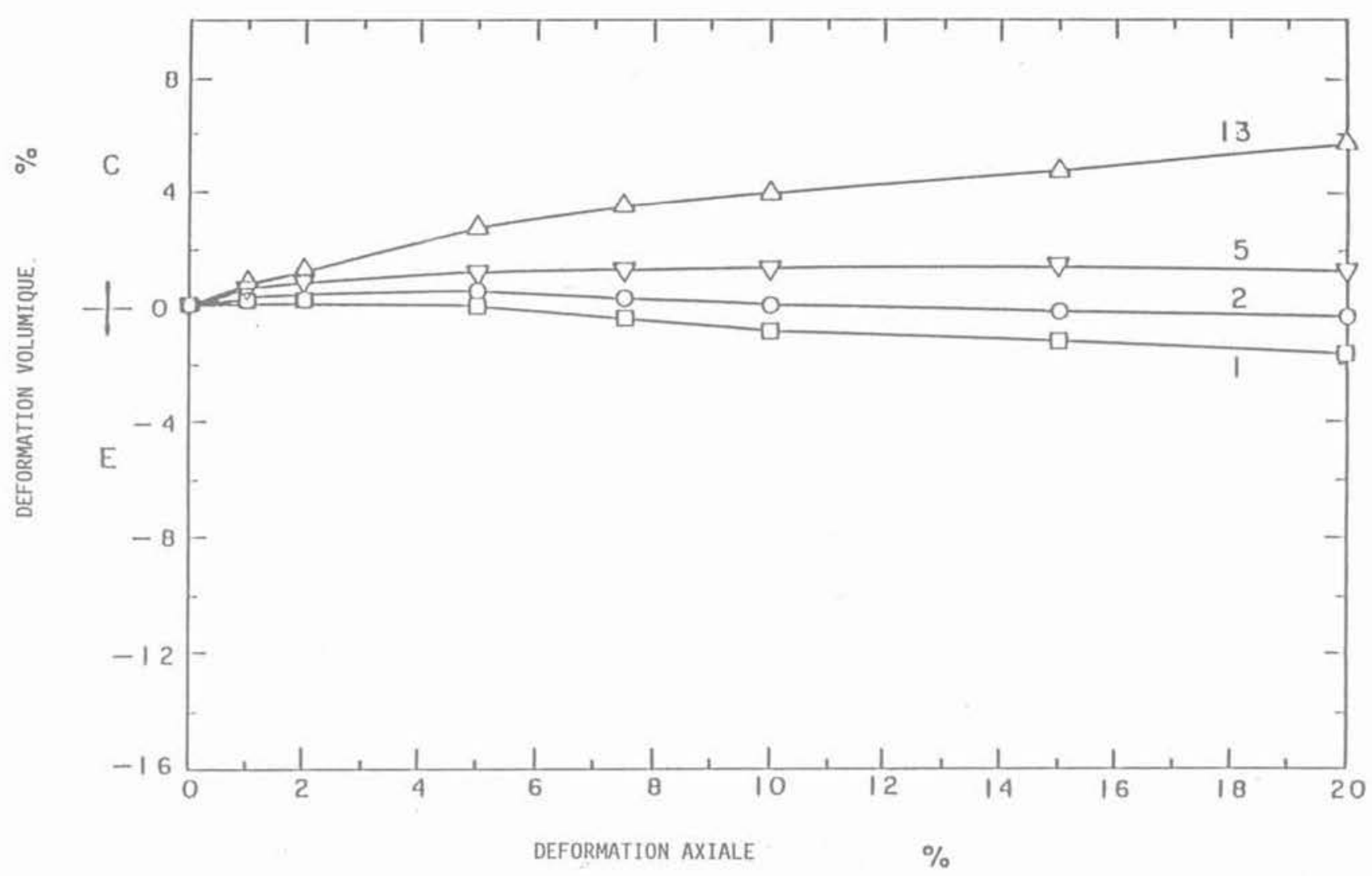

Fig. 2 b. - Valeurs de la déformation volumique correspondant à la figure 2 a. Fig. 2 b. - Volumetric strain data corresponding to (a).

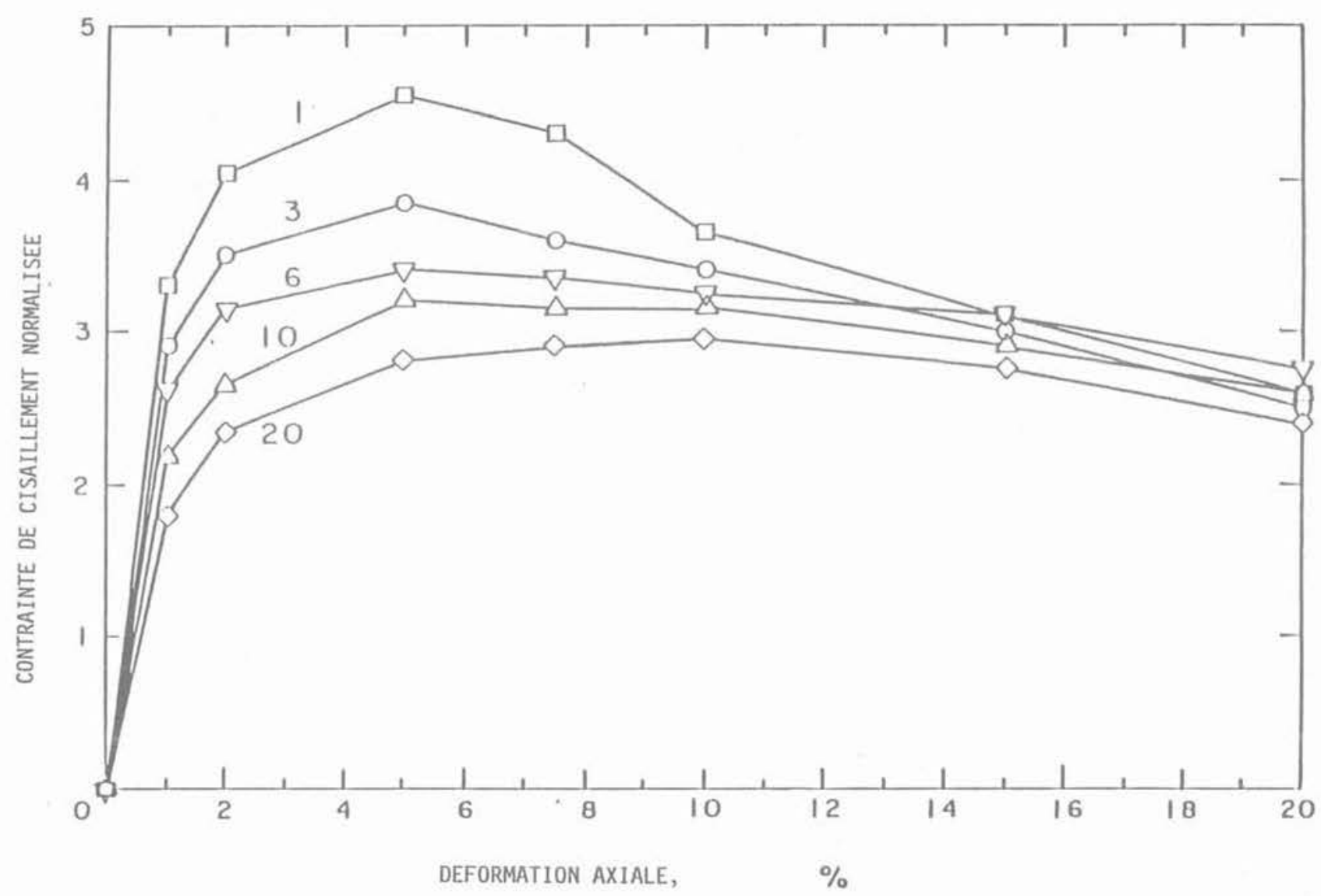

Fig. 3 a. - Courbe de contrainte-déformation pour un essai de compression triaxiale (10) pour un sable dense $(D$, $=100 \%)$, aux pressions de confinement indiquées sur les courbes.

Fig. 3a. - Triaxial compression test stress-strain data $(10)$ for a dense sand $\left(D_{1}=100 \%\right)$ at confining pressures marked on the curves: 


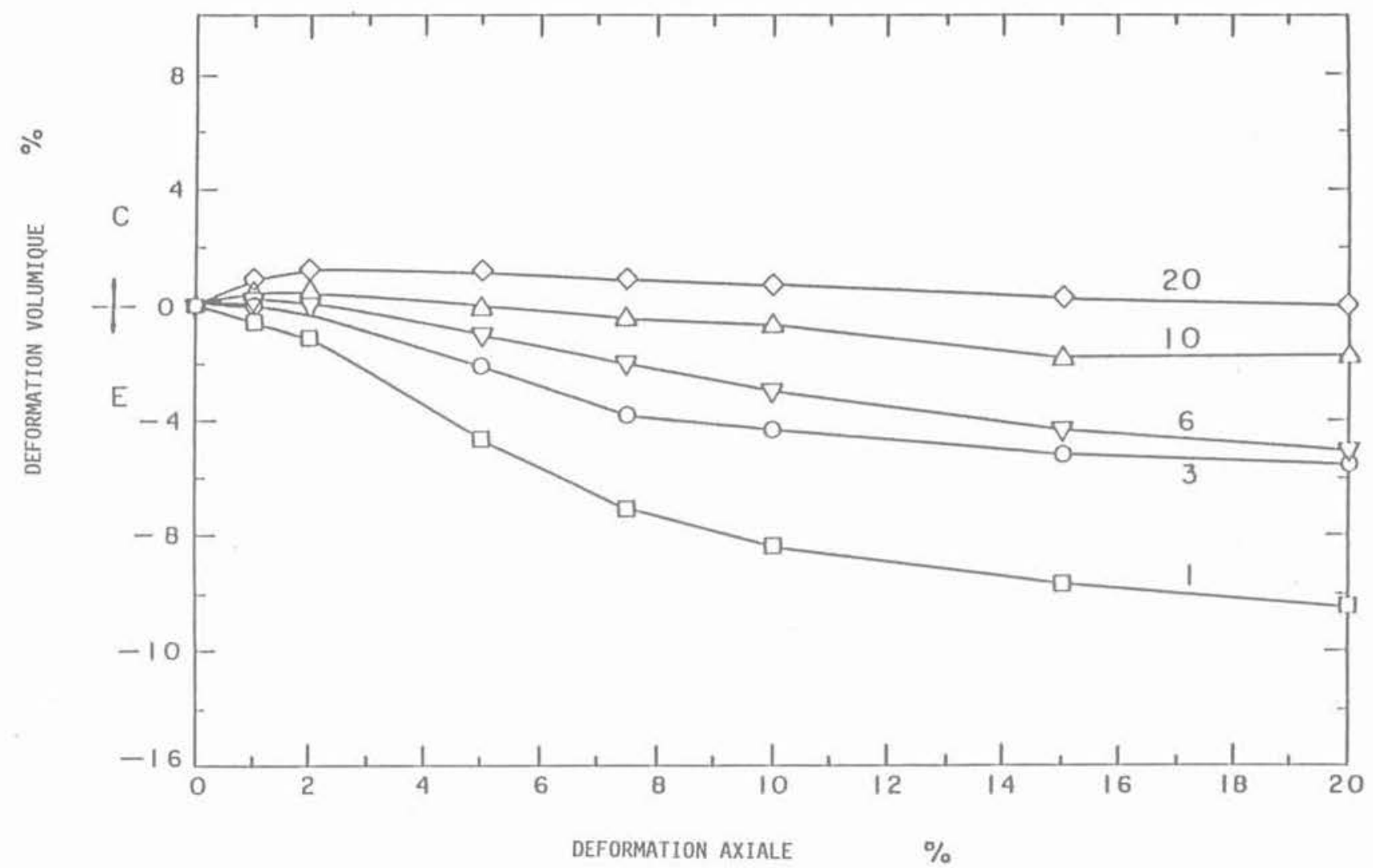

Fig. 3 b. - Valeurs de la déformation volumique correspondant à 3 a.

Fig. $3 b$, - Volumetric strain data corresponding to $(a)$.

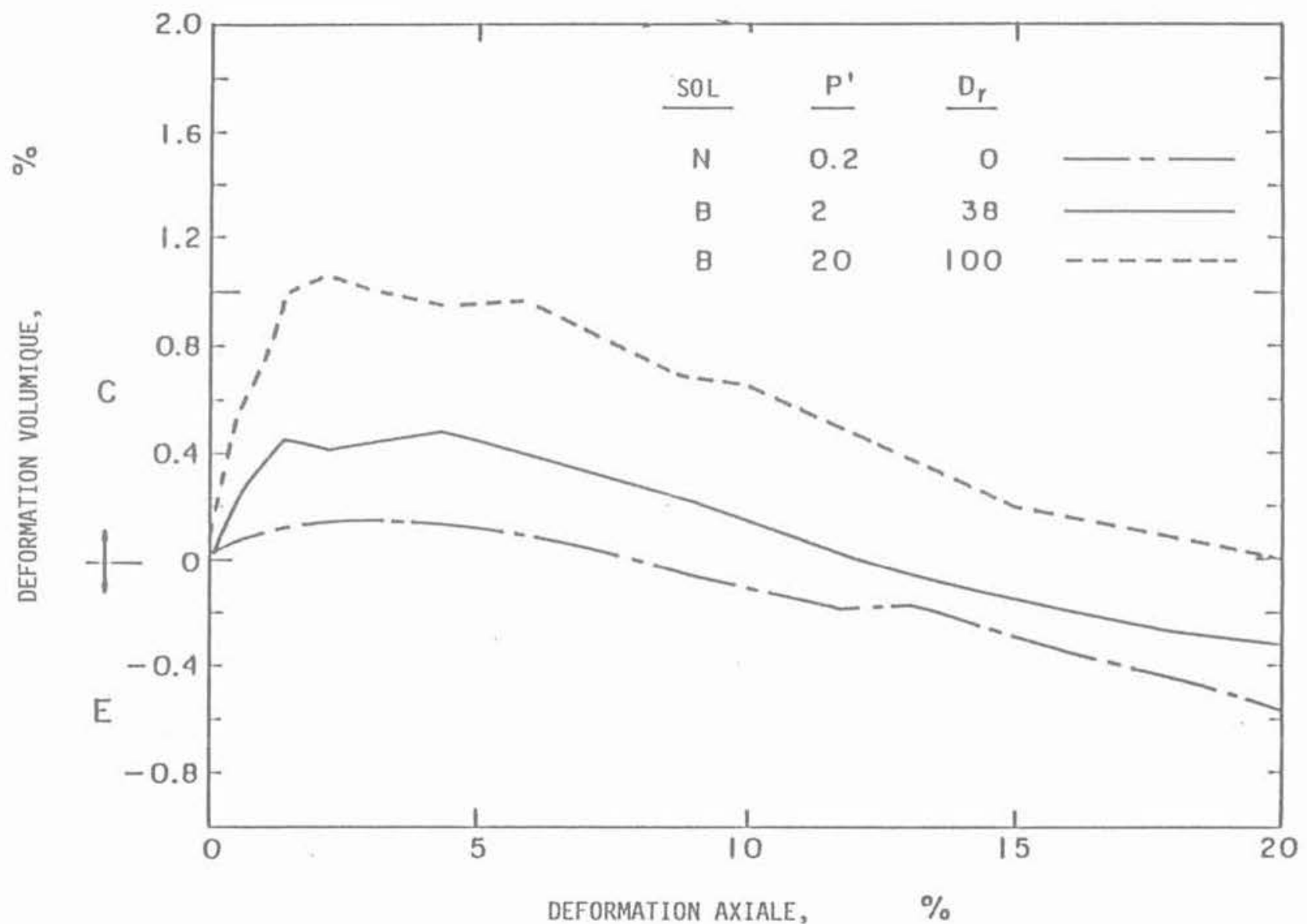

Fig. 4 a. - Déformations volumiques pour des essais sur des spécimens pour lesquels les déformations sont faibles. Fig. 4 a. - Volumetric strains for test specimens in which small volumetric strains occurred. 


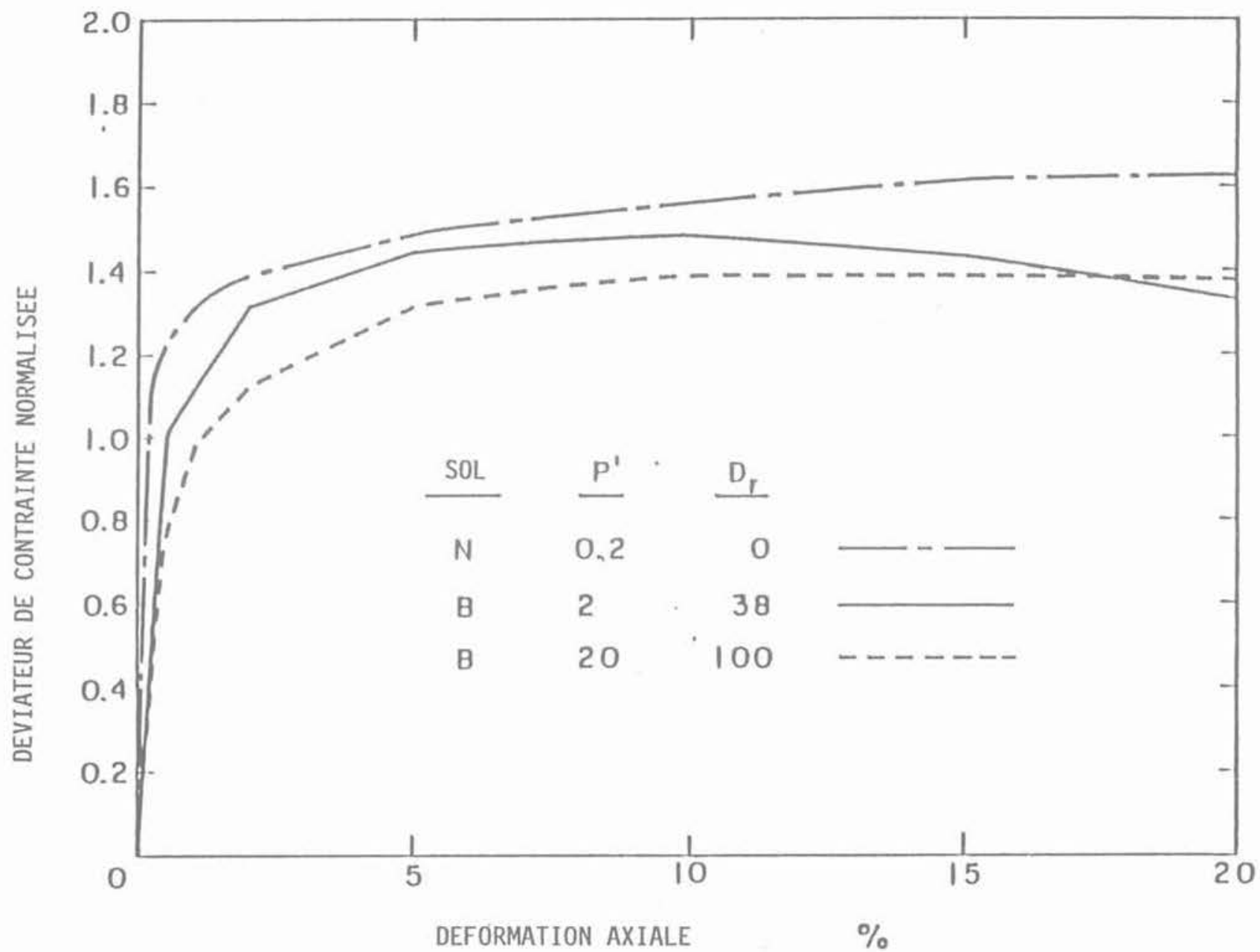

Fig. 4 b. - Courbe contrainte-déformation normalisée pour les essais de type (a) dans lesquels la contrainte de cisaillement était normalisée en divisant les différences des contraintes principales par la contrainte effective hydrostatique $p^{\prime}$,

Fig. $4 b$. - Normalized stress-strain data for the tests of $(a)$, in which the shearing stress was normalized by dividing the principal stress difference by the hydrostatic effective stress, $p$ '.

deux des résultats d'essais sont pour le même sol (B) mais le troisième se rapporte à un sol différent $(\mathrm{N})$. Si l'on accepte que la figure $4 \mathrm{~b}$ montre des mêmes comportements contrainte de cisaillement-déformation, alors on peut conclure qu'un essai prototype sur le sol $\mathrm{B}$ à une densité relative de $100 \%(\mathrm{p}=2,0)$ pourrait être simulé correctement par un modèle au $1 / 10^{e}$ avec le sol B pour une densité relative de $38 \%$ $\left(\mathrm{p}=\right.$.2) ou par un modèle réduit au $100^{\mathrm{e}}$ avec le sol $\mathrm{M}$ à une densité relative de $0 \%(\mathrm{p}=0,02)$. De même, un essai prototype sur le sol B à une densité relative de $38 \%$ serait correctement simulé par un essai au $1 / 10^{e}$ avec le sol $\mathrm{N}$ a une densité relative de $0 \%$.

\subsection{Conditions pour la modélisation à $1 \mathrm{~g}$}

Si ces résultats sont considérés comme un essai de formulation de relations de similitude pour des sols, les conditions pour une similitude correcte des essais sur modèle réduit à $1 \mathrm{~g}$ peuvent être définies comme suit.
1. Le facteur d'échelle des longueurs $x^{*}(=n)$ est fixé.

2. Une densité relative est choisie ou fournie pour le sol prototype. A ce stade, la densité relative du modèle peut être déterminée par des essais comme suit.

3. Une contrainte est calculée (de préférence une contrainte effective hydrostatique) à une profondeur appropriée pour le sol prototype ou pour un niveau de chargement représentatif de la structure (poutre, semelle, mur de soutènement).

4. Le comportement en déformation volumique est déterminé, à partir d'un essai en compression triaxiale ou d'un autre essai à la densité relative du prototype et pour la contrainte définie ci-dessus.

5. Par une série d'essais triaxiaux, au niveau de contrainte dans le modèle réduit au point homologue du prototype, on détermine la densité relative à laquelle la même déformation volumique se produit comme dans l'essai triaxial prototype.

6. Après avoir établi les propriétés de toutes les structures associées du modèle, en utilisant les relations 
du tableau 2 , on effectue l'essai sur le modèle réduit avec le sol à la densité relative déterminée au paragraphe 5 .

7. Les quantités mesurées sur le modèle sont converties en grandeurs prototypes par les relations données dans le tableau 2.

Comme alternative, ou comme guide pour obtenir la densité relative requise pour le modèle réduit, on peut utiliser un abaque qui a été préparé comme suit. Des données sur le comportemnet de différents sables ont été fournies par HETTLER et GUDEHUS [9], LADE [10], et d'autres $[5,8,11]$. Ces données ont servi à déterminer les lignes d'état critique standard pour le matériau comme montré par la figure 5. La densité relative, $D_{1}$ (au lieu de l'indice des vides) est portée, en fonction du logarithme de la contrainte moyenne, logp, pour obtenir un ensemble de valeurs homogènes et réduire la plage des ordonnées du diagramme. Sur ce diagramme chaque ligne à une pente, indiquée ici par $\lambda_{D}$ en raison de la similitude avec la pente de la ligne d'état critique. Pour les sols indiqués, $\lambda_{D}$ varie d'environ 10 pour les pentes les plus plates, à environ 40 pour les plus pentues.
L'équation d'une ligne typique est ainsi:

$$
D_{r}=D_{r 1}+\lambda_{D} \log (\mathrm{p} / 1)
$$

où $D_{r 1}$ est la densité relative pour $1 \mathrm{kN} / \mathrm{m}^{2}$

Comme discuté précédemment, on postule qu'un même comportement contrainte-déformation s'applique à un sol ayant des états d'indices des vides sur les lignes parallèles à la ligne CSL/SSL de la figure 1. Comme $D_{r}$, varie linéairement avec $e$, le même résultat est vrai pour la figure 5 et ainsi la densité relative pour des comportements semblables obéit à l'équation (21). Les deux états prototype et modèle se trouvent sur cette ligne. Ainsi deux équations peuvent être écrites:

$$
\begin{aligned}
& \text { prototype: } D_{r p}=D_{r s}+\lambda_{D} \log \left(p_{p} / 1\right) \\
& \text { modèle: } D_{r m}=D_{r s}+\lambda_{D} \log \left(p_{m} / 1\right)
\end{aligned}
$$

où $D_{r}$ est la densité relative à $\mathrm{p}=1$ pour la ligne de pente $\lambda_{D}$ passant par le point représentatif de la densité relative du sol prototype et de la contrainte moyenne du prototype $\left(\mathrm{p}_{\mathrm{p}}\right)$. En soustrayant $(22 \mathrm{~b})$ de (22 a) on obtient:

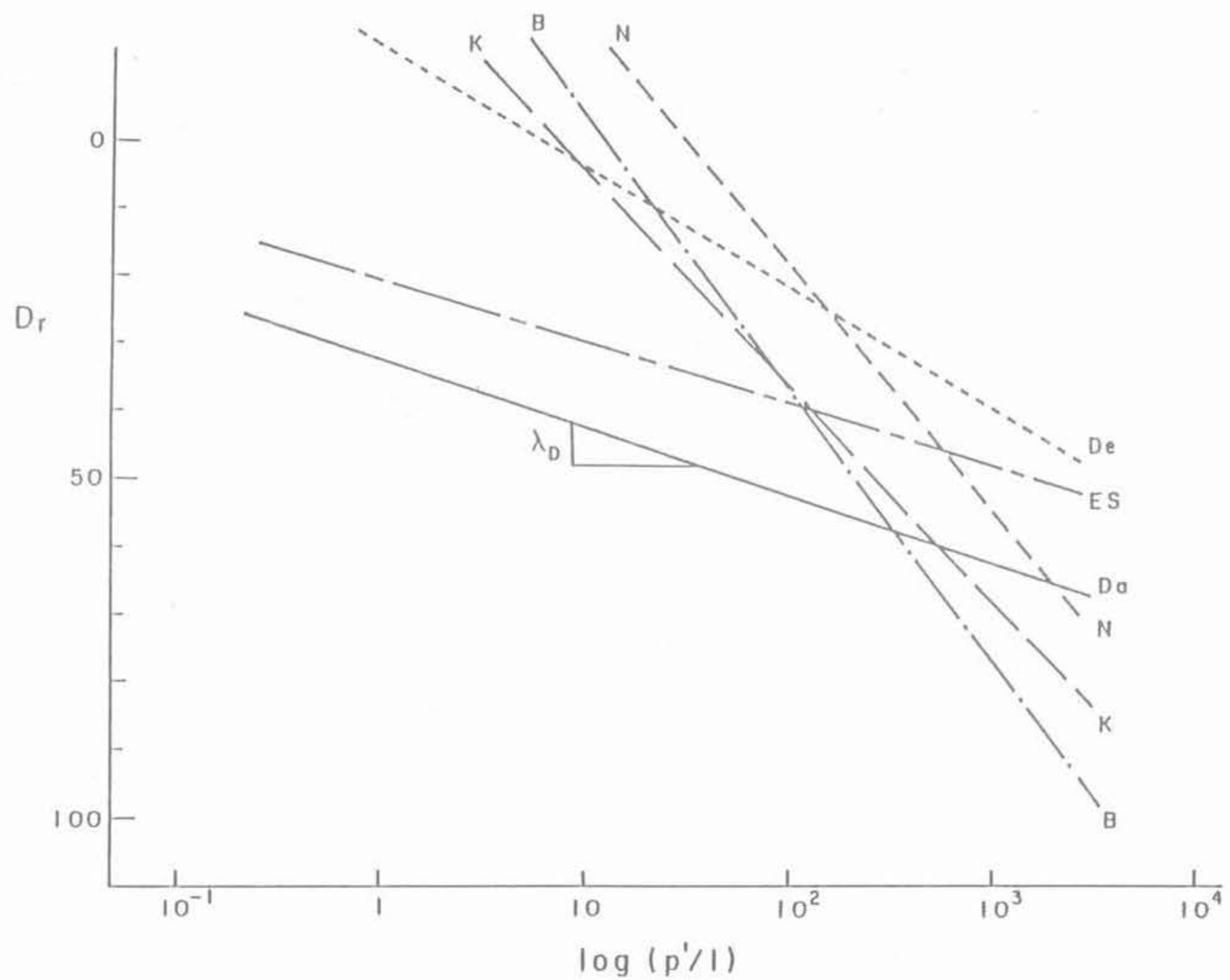

Fig. 5. - Lignes d'état critique données ou déduites pour différents sables $(9,10)$ en fonction de la densité relative. Fig. 5. - Critical steady state lines obtained or inferred for a number of sands 19,10$)$ plotted in terms of relative density. 


$$
D_{r m}=D_{r p}-\lambda_{D} \log _{10}\left(p_{p} / p_{m}\right)
$$

ou

$$
D_{r m}=D_{r p}-\lambda_{D} \log _{10} n
$$

dans laquelle :

$$
\mathrm{n}=\frac{\mathrm{p}_{\mathrm{p}}}{\mathrm{p}_{\mathrm{m}}}
$$

est le rapport d'échelle des longueurs recherché entre le prototype et le modèle réduit. La relation entre $D_{r m}$ et $D_{r P}$ est indépendante des niveaux réels de contrainte dans le modèle et le prototype.

Une représentation graphique de l'équation 23 b est donnée par la figure 6 pour les deux valeurs $\lambda_{D}$ représentant les réponses les plus plates et les plus pentues de la figure 5 . Si $\mathrm{n}=1$, bien sûr le pro- totype et le modèle sont identiques et $D_{r m}=D_{r p}$. Pour d'autres rapports de similitude, ils sont différents. Par exemple si $\lambda_{D}=10$ et $n=100$, une densité relative du prototype de $50 \%$ doit être simulée par $\mathrm{D}_{\mathrm{rm}}=30 \%$.

Avec $\lambda_{D}=40$, une densité relative du prototype de $40 \%$ à une échelle de 50 nécessite une valeur $D_{\text {rm }}$ du modèle $D_{r m}$ de $12 \%$.

Pour des sols ayant de faibles valeurs de $\lambda_{D}$, l'équation ( $23 \mathrm{~b}$ ) et la figure montrent que les densités relatives du prototype et du modèle réduit seront proches, même pour de grandes valeurs de n. Au contraire, une valeur élevée de $\lambda_{D}$ nécessite une densité relative du modèle notablement plus faible que celle du prototype pour un rapport d'échelle donné. La figure 6 explique aussi un certain nombre d'observa-

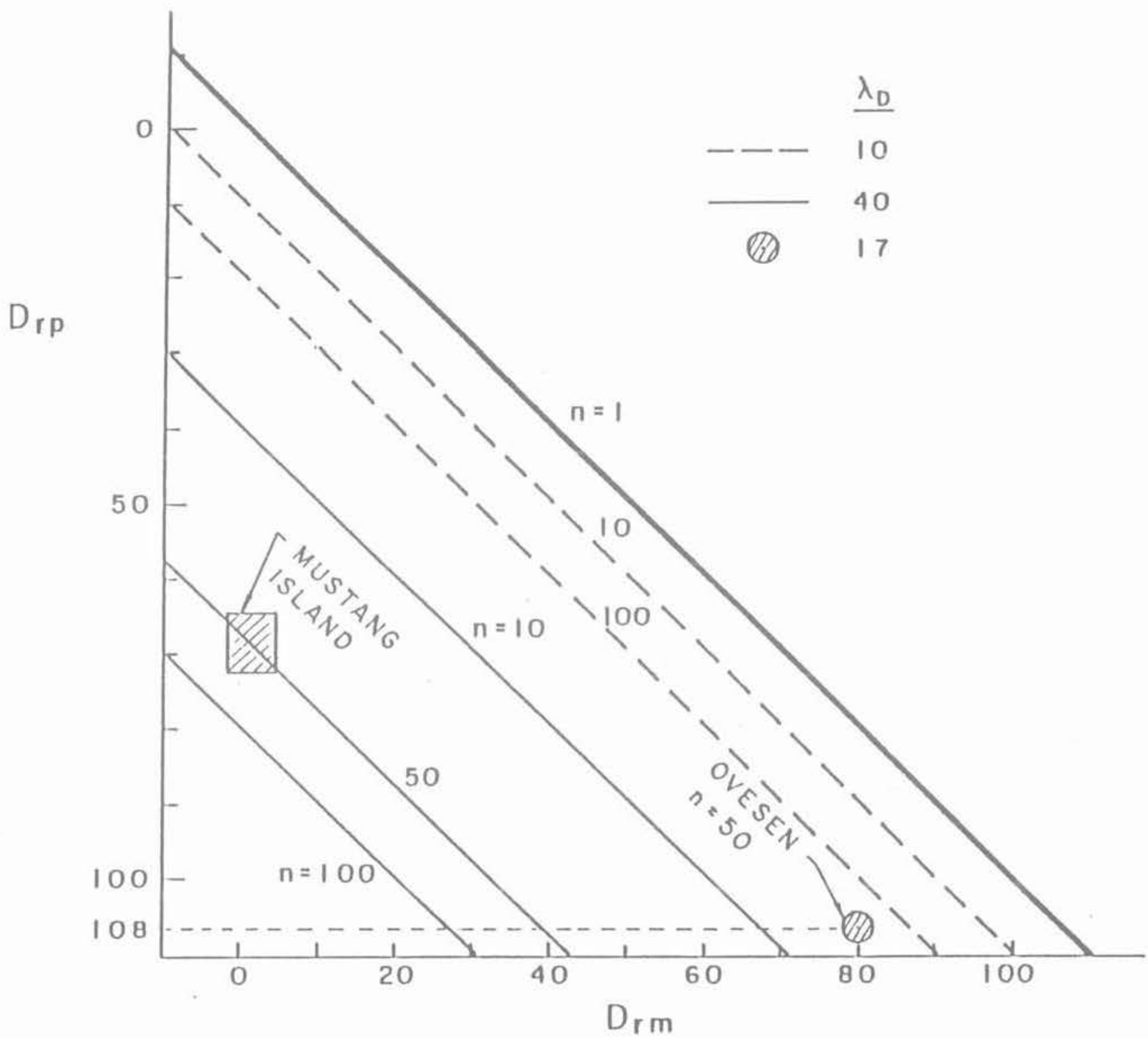

Fig. 6. - Densité relative du sable du modèle en fonction de la densité relative prototype pour différentes échelles de modélisation ot propriétés du sable.

Fig. 6. - Relative density of model sand in terms of relative density of prototype for various modelling scales and sand property. 
tions expérimentales. Comme noté plus haut, il est fréquent dans des problèmes aux limites en place et en laboratoire d'employer la même valeur de densité relative pour toutes les tailles d'objets testés. Pour des essais en place, des dimensions de $0,2,0,5,1 \mathrm{~m}$ seront employées; en laboratoire, pour des essais en centrifugeuse, $1,2,5 \mathrm{~cm}$, tous, à la même densité relative. Dans certains essais, par exemple, des problèmes de capacité portante ou d'effort d'arrachement d'ancrage, des résultats d'essais, tels que la résistance ultime normalisée, peuvent être relativement peu dépendant de la taille de l'objet testé, quand le même sol est utilisé à la même densité relative. La figure 6 indique que l'on peut s'attendre à ce résultat (avec les tolérances usuelles) si $\lambda_{p}$ est faible pour le sol en question. En revanche, des différences sont quelquefois observées entre des résultats normalisés, avec les mêmes conditions d'essais, pour des semelles de fondation, ou d'autres objets, ayant disons de 1 à $5 \mathrm{~cm}$ de diamètre. Ceci est le cas quand $\lambda_{\text {Dest }}$ grand, et ceci est usuellement décrit comme "effet d'échelle». Dans la figure 6, à titre d'illustration, pour $\lambda_{D}=40$, des comportements semblables peuvent seulement être attendus pour des semelles de $5 \mathrm{~cm}$ "prototype» et $1 \mathrm{~cm}$ ("échelle réduite») avec le même sol si la densité relative du modèle est de $28 \%$ plus faible que celle du "prototype». Ces chiffres sont seulement approximatifs, et donnés à titre d'illustration, car l'ensemble des essais nécessaires pour établir les figures 5 et 6 correctement n'ont pas été encore effectués ni rassemblés.

A titre d'exemple, OVESEN [13] présente des résultats d'essais sur la résistance à l'arrachement d'ancrages. Dans sa figure 7 , des résultats sont donnés pour des essais en centrifugeuse à $50 \mathrm{~g}$ et des essais sur modèle à $1 \mathrm{~g}$ sur du sable à deux densités relatives $36 \%$ et $108 \%$ pour les deux sols testés. Ici les essais en centrifugeuse sont «le prototype» pour les ancrages circulaires et les essais à $1 \mathrm{~g}$ sont les essais à "échelle réduite». Pour une même valeur $D_{r}$ il y a des différences entre les efforts d'arrachement normalisé du prototype et du modèle. Par interpolation dans le diagramme, on peut trouver approximativement

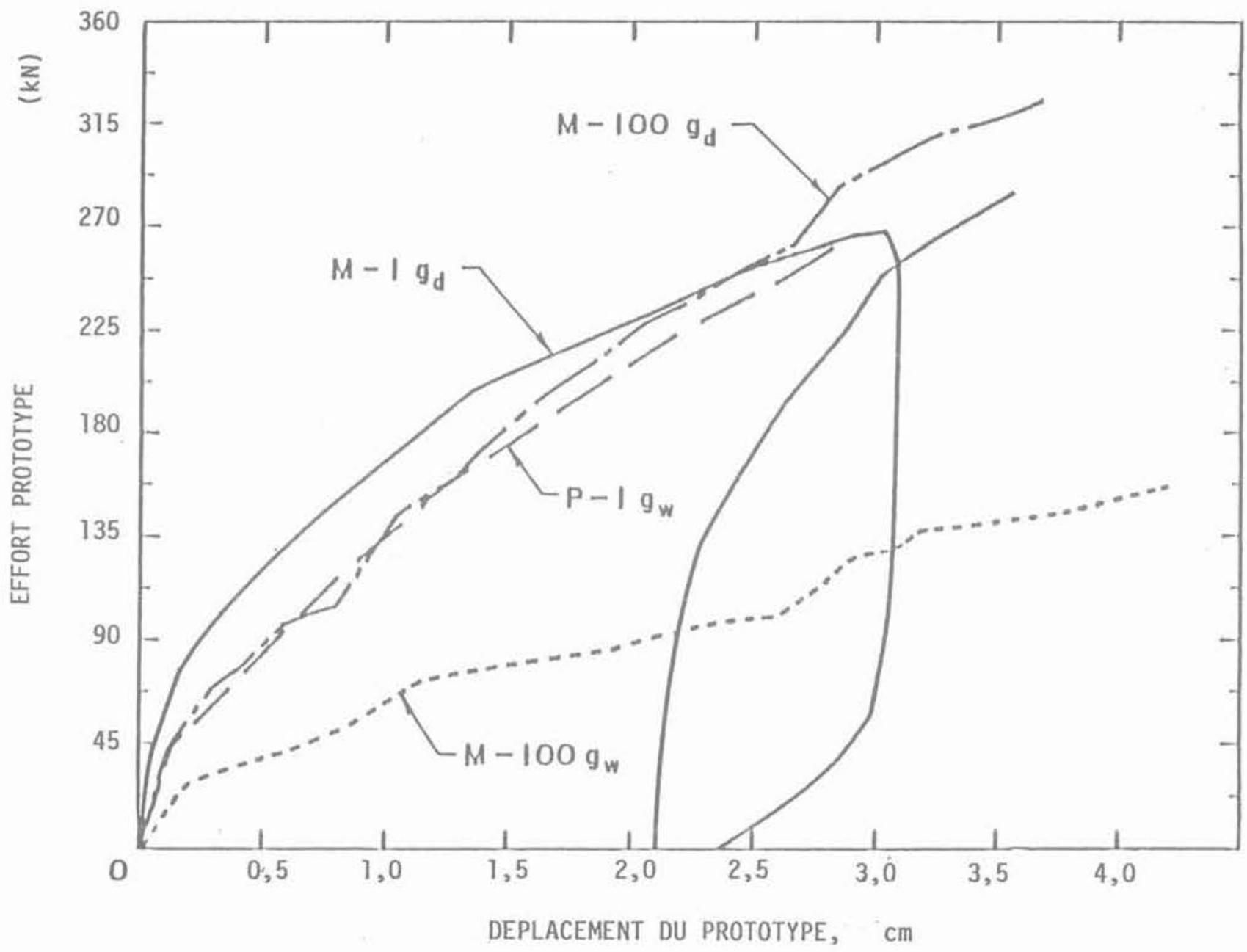

Fig. 7. - Comparaison des courbes effort latéral-déplacement à l'échelle prototype pour le pieu prototype (P-1 g), modèle du pieu au $1 / 100^{e}$ en centrifugeuse $(\mathrm{M}-100 \mathrm{~g}$ ), et modèle du pieu au 1/48 à $1 \mathrm{~g}(\mathrm{M}-1 \mathrm{~g})$. Les indices se rapportent aux essais sur sable sec ou humide.

Fig. 7. - Comparison of lateral load-displacement curves at prototype scale for prototype pile (P-1 g), 1/100 model pile in centrifuge $(\mathrm{M}-100 \mathrm{~g})$, and $1 / 48$ model pile at one-g $(\mathrm{M}-1 \mathrm{~g})$. The subscripts refer to dry or wet sand tests. 
que si les essais sur modèle avaient été réalisés à environ $D_{r m}=80 \%$, ils auraient correspondu au résultat prototype (centrifugeuse) $D_{p}=108 \%$. En reportant ce point sur la figure 6 ou en appliquant l'équation (23 b) avec $n=50$ on obtient une valeur $\lambda_{D}$ $=16,5$ pour le sable utilisé par OVESEN (sable standard Dansk $n^{\circ} 1$ ). La valeur réelle n'est pas connue de l'auteur.

Pour chaque valeur $\lambda_{D}$ pour des sols différents, il $y$ a une valeur prototype $D_{\mathrm{rp}}$ limite. En dessous de cette valeur, on ne peut pas effectuer d'essai sur modèle car la valeur du modèle $D_{r m}$ est toujours plus faible que celle du prototype, et qu'elle ne peut pas en pratique être très inférieure à $0 \%$. Cependant, un autre sol peut être trouvé comme indiqué par les sols $B$ et $N$ des figures 4 et 5 en utilisant les critères de similarité du comportement en variation de volume. Ce sol serait lui préparé à une valeur possible de $D_{r m}$ et donnerait des résultats acceptables. Il se trouve que les sols $B$ et $N$ ont des valeurs de $\lambda_{D}$ proches. Des comportements contrainte-déformation semblables peuvent ne pas être obtenus pour des sols ayant des valeurs $\lambda_{D}$ différentes mêmes si les déformations volumiques sont les mêmes. Ceci reste à analyser.

\section{5. ÉTUDE EXPÉRIMENTALE DE CES HYPOTHÈSES}

Il semblait valoir la peine de tester les hypothèses précédentes en effectuant un essai sur modèle à $1 \mathrm{~g}$. Comme les relations de similitude données dans le tableau 2 s'appliquent à la fois au sol et à la structure, on a considéré qu'une estimation correcte pouvait être obtenue en effectuant un essai de chargement latéral sur un pieu flexible plutôt que par l'intermédiaire d'une procédure d'essai plus usuelle incorporant un élément de structure rigide. De plus, il est apparu souhaitable de simuler un prototype réel et, si possible, de comparer les résultats avec ceux des essais en centrifugeuse. L'essai de chargement latéral sur un pieu de l'lle Mustang fut choise pour cette étude [4]. L'auteur avait essayé précédemment de reproduire cet essai en centrifugeuse sans succès net bien que des meilleurs résultats aient été obtenus par BARTON [1]. La médiocre comparaison précédente pouvait avoir été due à une mauvaise représentation du pieu (EI correcte, mais diamètre trop petit), par une mauvaise correspondance entre le sol du modèle et du prototype, où par un sol prototype plus raide que ne l'indiquait sa densité relative. Quelqu'en soit la raison, la relation déplacement-effort en tête du pieu, avec un sol prototype saturé moyennement dense à dense n'a pu être reproduite sur le modèle en centrifugeuse qu'avec un sol sec moyennement dense à dense.

Sans données complètes sur le sol prototype, à l'exception de la taille des grains, le sable caractérisé par le comportement $\mathrm{N}$ sur la figure 5 a été utilisé à la fois en centrifugeuse et pour des essais à $1 \mathrm{~g}$ que nous allons décrire. Ce sable a un $\lambda_{D}$ de l'ordre de 40. Il n'y a pas d'information suffisante pour estimer le $\lambda_{D}$ du sol prototype. Avec un facteur d'échelle d'environ 50 , la figure 6 indique qu'un sable prototype moyennement dense à dense implique que l'on utilise en laboratoire un sable proche d'une densité relative égale à $0 \%$. Les sables du prototype et du modèle sont tous deux uniformes et fins avec un diamètre moyen d'environ $0.1 \mathrm{~mm}$. Le sable du modèle était placé dans un conteneur $0,37 \times 0,27 \times$ $0,20 \mathrm{~m}$ en le déversant pour obtenir la densité relative faible recherchée. La valeur finale de $D_{r m}$ fut de $7 \%$. Le pieu prototype était un tube d'acier de $0,61 \mathrm{~m}$ de diamètre extérieur, de $12,5 \mathrm{~mm}$ d'épaisseur et d'une longueur d'environ $17 \mathrm{~m}$. Le facteur d'échelle de $\mathrm{n}^{5}$ pour El aurait nécessité un pieu modèle tubulaire d'environ $12,5 \mathrm{~mm}$ de diamètre mais avec une épaisseur de moins de $0,02 \mathrm{~mm}$. Un tel tube n'étant pas disponible, il fut décidé de représenter le pieu par une bande d'aluminium de $12,5 \mathrm{~mm}$ de large pour obtenir un facteur d'échelle de 48 . Une épaisseur de $0,2 \mathrm{~mm}$ pour la bande d'aluminium fut retenue pour obtenir le EI du prototype. Comme la flexion sous charge latérale est localisée entièrement dans la portion supérieure du pieu sur une hauteur de 10 à 15 fois le diamètre du pieu, la reproduction de la longueur du pieu n'était pas importante; le pieu modèle était long de $0,2 \mathrm{~m}$. L'effort latéral était appliqué au pieu prototype à $0,3 \mathrm{~m}$ au-dessus de la surface du sol, mais il n'était pas clair si le déplacement était mesuré en ce point ou à la surface du sol. Dans le pieu modèle, l'effort et le déplacement étaient mesurés à $6,3 \mathrm{~mm}$ audessus de la surface du sol.

Plusieurs essais ont été menés sur le pieu installé en différents endroits du même massif de sol. L'effort latéral était appliqué par un câble de nylon reliant le pieu à un dispositif de chargement entraîné par un moteur par l'intermédiaire d'un capteur de force. Deux minutes environ étaient nécessaires pour produire un déplacement équivalent prototype de $25 \mathrm{~mm}$. Les déplacements étaient mesurés par un capteur LVDT également attaché au câble. Après étalonnage des capteurs de force et de déplacement, et multiplication par les facteurs d'échelle $\mathrm{n}^{3}$ et $\mathrm{n}$, respectivement, l'effort et le déplacement prototype sont représentés sur la figure 7 pour un essai de chargementdéchargement-rechargement typique. Sur la même figure sont présentés les résultats de l'essai prototype original avec sol saturé et des 2 essais en centrifugeuse effectués il y a 10 ans [20] sur sable sec et saturé placés à la même densité que le prototype.

On peut voir que l'essai sur modèle réduit à $1 \mathrm{~g}$ avec un sable sec très lâche se compare bien avec les résultats du prototype et de l'essai sur modèle réduit en centrifugeuse sur un sable moyennement dense, bien que le sol prototype soit saturé. Vraisemblablement l'essai à $1 \mathrm{~g}$ sur un sable lâche dans des conditions saturées (ce qui n'a pas encore été effectué) aurait donné des résultats comparables à l'essai en centrifugeuse à $100 \mathrm{~g}$ sur un sable moyennement dense saturé. Dans le rapport original, l'écart entre les essais prototype et en centrifugeuse était imputé à une modélisation incorrecte de la largeur du pieu modèle et à un sable prototype plus raide que ne l'indiquait son état de densité. L'article de BARTON [1] qui 
montre une correspondance remarquable entre prototype et essai en centrifugeuse, ne décrit pas les conditions de préparation du sol ni sa densité pour les essais en centrifugeuse. Comme la largeur du prototype était représentée correctement dans les essais à $1 \mathrm{~g}$ rapportés ici (bien que la forme soit différente), il est vraisemblable qu'une meilleure représentation des résultats du prototype pourrait être obtenue avec des essais sur modèle réduit à $1 \mathrm{~g}$ avec un sable modèle saturé légèrement plus dense.

\section{CONCLUSIONS}

Une diversité de structures prototypes du domaine géotechnique a été considérée du point de vue de la représentation de leur comportement sur des modèles à échelle réduite. Un certain nombre de conclusions sont données dans le tableau 1. A partir de ce résumé, la discussion a été centrée sur les relations d'échelle et les conditions nécessaires pour la similitude du comportement entre modèle et prototype. En guise de résultats, une méthode a été présentée, basée sur un tout premier examen de résultats d'essais sur des sables, et sur quelques postulats tirés du modèle Camclay pour le comportement du sol. Selon cette analyse, des essais sur modèle réduit à $1 \mathrm{~g}$ peuvent être envisagés pour représenter correctement le comportement de sol et de structures prototypes. En résumé, la méthode demande que le sol du modèle à échelle réduite soit préparé à une densité relative plus faible que celle du prototype afin que sa réponse soit similaire à celle du prototype lorsque l'on suit un même chemin de contrainte réduit par le facteur d'échelle approprié. En particulier, le sol du modèle réduit présentera les mêrnes déformations volumiques, pour la même plage de contrainte de cisaillement à l'échelle, au niveau de contrainte réduite par le facteur d'échelle, que pour le sol prototype pour des contraintes plus élevées. Une figure est proposée pour guider le choix de la densité relative du sol du modèle réduit une fois donnée la densité relative du (même) matériau prototype, et ses caractéristiques d'état critique. Il est souligné que ces résultats sont préliminaires. En particulier, davantage d'essais doivent être effectués pour caractériser le comportement du sol sous des contraintes de confinement très faibles (moins de $1 \mathrm{kPa}$ ) et pour des densités faibles appropriées pour les essais sur modèles réduits. Il est possible que les concepts d'état critique ne s'appliquent pas dans cette situation. Dans ce cas, l'utilisation pour le modèle d'un sol à une densité qui donnera les mêmes déformations volumiques que le prototype (à un niveau de contrainte plus élevé) peut cependant donner des conditions de modélisation satisfaisantes. Les essais en laboratoire sur échantillons homogènes effectués avec des appareils triaxiaux, de déformation plane sur échantillons cubiques pouvant donner des résultats différents, si bien que certains de ces essais seront plus appropriés (essais en déformation plane par exemple) pour certaines expériences aux limites à échelle réduite. Pour certains problèmes aux limites, des contraintes de traction [17], la fracturation, ou des déformations très importantes peuvent se développer. Il paraîtrait souhaitable d'étudier les similitudes du comportement dans ces cas, par des essais en extension appropriés.

La figure 4 démontre que deux sables différents peuvent exhiber les mêmes réponses en contraintedéformation avec des densités relatives et des niveaux de contraintes différents si les comportements en déformation volumique sont les mêmes. Ceci offre la possibilité de substituer au sable prototype un sable différent pour des essais sur modèle réduit à $1 \mathrm{~g}$.

Bien que la discussion ait porté spécifiquement sur des sables, les mêmes considérations sur l'état critique s'appliquent aux argiles. Dans leur cas, la densité relative n'est pas le paramètre approprié, et peut être remplacé par l'indice des vides, la teneur en eau, ou le rapport de surconsolidation (OCR). Aucun examen n'a été fait ici de ce point mais probablement la même argile à deux états de pressions de consolidation différents, dont le rapport définit le facteur d'échelle n, exhiberont le même comportement contraintedéformation si on les soumet à des chemins de contraintes semblables, si les deux états de consolidation correspondent au même OCR. Ceci se substitue et inclut la condition usuelle simple de similitude sur la résistance des sols cohérents, déduite de considérations dimensionnelles, selon laquelle $c / \gamma \mathrm{L}$ est constant dans le prototype et pour les essais à échelle réduite (c est la résistance de cisaillement, $\gamma$ poids volumique, et $\mathrm{L}$ une longueur caractéristique).

Peut être l'une des meilleures illustrations de la discussion précédente est contenue dans la communication de MIKASA et TAKADA [12] relative à des essais de capacité portante de semelles. Une semelle de $2 \mathrm{~cm}$ sur un sable moyennement dense saturé était chargée jusqu'à rupture à $1 \mathrm{~g}$ en laboratoire et à $40 \mathrm{~g}$ dans une centrifugeuse où elle représentait un prototype de $0,8 \mathrm{~m}$ de large. Les deux essais étaient effectués à la même densité relative. Des photos de la déformation du sable dans ces essais en déformation plane étaient prises à travers la vitre du conteneur et présentées par la figure 8. Dans l'essai à $1 \mathrm{~g}$ le mécanisme du déplacement est clairement celui d'une rupture générale avec le coin de pénétration caractéristique sous la semelle et les éventails de lignes de glissement de chaque côté. Au contraire, l'essai en centrifugeuse indique une rupture locale associée à une diminution substantielle du volume du sol chargé. La conclusion est qu'avec de faibles contraintes à $1 \mathrm{~g}$ le sol est dilatant avec un comportement contrainte-déformation instable et développement de surfaces de glissement, alors qu'à $40 \mathrm{~g}$, le même sol est contractant avec un comportement contraintedéformation stable et sans formation de ligne de glissement. Dans l'essai à $1 \mathrm{~g}$, le tassement de la semelle était da aux déformations de cisaillement dans le sol; à $40 \mathrm{~g}$ il était dû principalement à des déformations volumiques contractantes. Un tel résultat peut à la fois servir pour justifier des essais en centrifugeuse et adopter les mêmes contraintes dans le modèle et le prototype, ou pour illustrer l'effet d'une mauvaise densité relative retenue pour le modèle. 


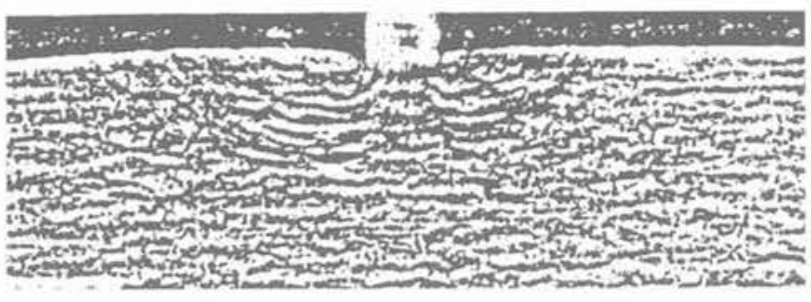

a) Champ de pesanteur terrestre $(1 \mathrm{~g})$

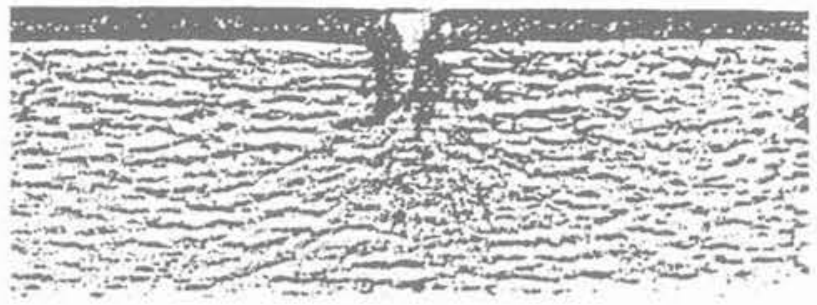

b) Accélération centrifuge $(40 \mathrm{~g})$

Fig. 8. - Photographies des essais de capacité portante de Mikasa (12) sur des modèles réduits de semelle au $1 / 40^{\circ}$ sur sable saturé à $77 \%$ de densité relative à $1 \mathrm{~g}$ et en centrifugeuse à $40 \mathrm{~g}$. La densité du sable était la même dans les deux essais.

Fig. 8. - Photographs of Mikasa's (12) bearing capacity tests on a $1 / 40$ scale model footing in saturated sand of $77 \%$ relative density at one-g, and in a centrifuge at $40 \mathrm{~g}$. Sand density was the same in both tests.

Une intention de ce rappel est de mettre en évidence que la caractéristique intéressante des essais en centrifugeuse - la représentation du comportement contrainte-déformation réelle des matériaux géotechniques en grandeur réelle - ne devrait pas exclure totalement la réalisation d'essais en laboratoire ou sur site à $1 \mathrm{~g}$, si ces derniers sont entrepris correctement avec des matériaux préparés avec une similitude appropriée. Par ordre décroissant de complexité et de coût se situent les essais en vraie grandeur, en centrifugeuse et finalement des expériences à $1 \mathrm{~g}$. Dans nombre de cas, la solution la plus économique peut être d'effectuer plusieurs essais à échelle réduite (qui n'ont pas besoin d'être aussi petits que $1 / 100^{e}$ ) à $1 \mathrm{~g}$ pour établir des effets de variation des paramètres, en les accompagnant d'un nombre plus réduit d'essais en centrifugeuse ou prototype. Pour des raisons évidentes, quelques essais en vraie grandeur devraient toujours être faits chaque fois que possible.

\section{REMERCIEMENTS}

Certaines des considérations sur la modélisation développées dans la première partie de cet article ont été avancées par le Dr M. BALIGH du MIT en 1985. dans une discussion sur les usages et abus des centrifugeuses géotechniques. Je suis reconnaissant à $\mathrm{R}$. $\mathrm{BECH}$ du Caltech qui m'a patiemment instruit dans les techniques de numérisation et de reproduction graphique sur ordinateur avec lesquelles j'ai préparé les premières versions des figures de cette communication.

\section{BIBLIOGRAPHIE}

1. BARTON Y.O., PANDE G.N. (1982), Laterally loaded piles in sand: centrifuge tests and finite element analyses. In Numerical Models in Geomechanics, R. Dungar, G.N. Pande an J.A. Studer, Eds, 749-758.

2. BEEN K., JEFFERIES M.G. (1986), "A state parameter for sands». Géotechnique, 35, (2), 99-112, 1985. Discussion, Géotechnique, 36 (1), 123-132.

3. CHAN S.F., HANNA T.H. (1980), « Repeated loading on single piles in sand». Proc. ASCE, 106, Jour. Geotechn. Eng. Div. (GT2), 171-188.

4. COX W.R., REESE L.C., GRUBBS B.R. (1974), «Field testing of laterally loaded piles in sand». Proc. 6th Annual Offsh. Tech. Conf., Paper $n^{\circ}$ OTC 2079, Houston, TX, May 1974.

5. DARVE $P$, , LABANIEH S. (1982), *Incremental constitutive law for sands and clays: simulations of monotonic and cyclic tests». Int. J. for Num. and Anal. Meth. in Geomechanics, 6, 243-275.

6. FUGLSANG L.D., KREBS OVESEN N. (1988), "The application of the theory of modelling to centrifuge studies». In Centrifuges in Soil Mechanics, W.H. Craig, R.G. James, and A.N. Schofield, Eds., 119-138, Balkema, Rotterdam.

7. HAKUNO M., IWASAKI T., TATSUOKA F. (1977), "Effects of soils liquefaction on dynamic behavior of pile foundations». Proc. Specialty Session 10, 9th Int. Conf. Soil Mech. and Found. Eng., Tokyo, 165-174.

8. HETTLER A., VARDOULAKIS I. (1984), "Behavior of dry sand tested in a large triaxial apparatus». Géotechnique, 34 (2), 183-198.

9. HETTLER A., GUDEHUS G. (1985), «A pressure-dependent correction for displacement results from $1 \mathrm{~g}$ model tests with sand». Géotechnique, 35, (4), 497-510.

10. LADE P. (1977), «Elasto-plastic stress-strain theory for cohesionless soil with curved yield sur. faces». Int. J. Solids and Structures, 13 (11), 1019-1035.

11. LEE K.L., SEED H.B., DUNLOP P. (1967), *Effect of moisture on the strength of a clean sand». Proc. ASCE, 93, J. Soil Mech. and Found. Div. (SM6), 17-40, November 1967.

12. MIKASA M., TAKADA N. (1973), "Significance of centrifugal model test in soils mechanics». Proc. 8th Int, Conf. on Soil Mech. and Found. Eng. 1.2, 273-278.

13. OVESEN N.K. (1981), "Centrifuge tests of the uplift capacity of anchors». Proc. 10th Int. Conf. Soil Mech. and Found. Eng., Paper 4-40, 717-722, Stockholm.

14. POULOS H.G. (1982), aInfluence of cyclic loading on axial pile response». University of Sydney, School of Civil and Mining Engineering Research Report n R413, May 1982. 
15. ROSCOE K.H., BURLAND J.B. (1968), «On the generalized stress-strain behavior of wet clay". In Engineering Plasticity, J. Heyman and F. Leckie, Eds., Cambridge Univ. Press, Cambridge, U.K., 535-609.

16. ROSCOE K.H., POOROOSHASB H.B. (1963), «A fundamental principle of similarity in model tests for earth pressure problems». Proc. 2nd Asian Conf. Soil Mech., 1, 134-140.

17. ROWE R.K., DAVIS E.H. (1982), «The behavior of anchor plates in clay». Géotechnique, 32 (1), 9-23.

18. ROWE R.K., DAVIS E.H. (1982), "The behavior of anchor plates in sand». Géotechnique, 32 (1), 25-41.

19. SCHOFIELD A.N., WROTH C.P. (1968), "Critical state soils mechanics». McGraw-Hill, NY.

20. SCOTT R.F. (1977), "Centrifuge studies of cyclic lateral load-displacement behavior of single piles . Final report for Amer. Pet. Institute OSAPR Project 8 , Calif. Inst, Techn. Pasadena, CA. 